\title{
Sorting of a sand-gravel mixture in a Gilbert-type delta
}

\author{
CARLES FERRER-BOIX *, JUAN P. MARTIN-VIDE $\dagger$ and GARY PARKER \\ *Department of Geography, The University of British Columbia, 1984 West Mall, Vancouver, BC V6T \\ 1Z2, Canada (E-mail: cfboix@geog.ubc.ca) \\ $\dagger$ Department of Hydraulic, Maritime and Environmental Engineering, Technical University of \\ Catalonia, C. Jordi Girona, 1-3, Barcelona 08034, Spain \\ $\$ 2527$ c Hydrosystems Laboratory, Department of Civil and Environmental Engineering and \\ Department of Geology, University of Illinois, 301 N. Mathews Ave., Urbana, IL 61801, USA
}

Associate Editor - David Mohrig

\begin{abstract}
This paper presents the results of a Gilbert-type delta progradation experiment within an impoundment created by a dam. The delta was composed of a poorly sorted sand-gravel mixture in a bedload-dominated environment. The main goal of the paper is to analyse the sorting process of material within the deposit as the delta progrades towards the dam. Bed profile evolution has been documented and the entire delta has been extensively sampled in order to study sorting processes. Longitudinal and vertical sorting mechanisms are illustrated. What is novel in this investigation is the complete record, within an entire deltaic deposit, of the vertical distribution of streamwise sorting in the absence of suspended load. The data presented herein provide a detailed description of sorting processes in a Gilbert-type delta. The experimental set-up, the water flow and the sediment feed rate chosen determine the evolution of the delta: it initially progrades with little topset aggradation and degrades afterwards. Experimental results fit well with a previously presented empirical sorting model, despite the fact that the experimental conditions used here were well outside the range of those used to derive that model. The relative coarsening of the upper layers of the delta is found to be related to the slow speed at which the delta progrades, the formation of a mobile armour layer and the erosion of the topset towards the end of the run. Furthermore, a strong correlation between the coarsening of the bottom layer of the delta and its front height has been documented and explained: as the delta gets higher, as there is more space to sort sediment, it is more likely that coarse particles failing near the top of the foreset reach the bottom of the foreset. These findings provide new and useful data documenting sediment sorting in granular, bedload-dominated deltas.
\end{abstract}

Keywords Empirical model, experiment, Gilbert-type delta, sorting, stratigraphy.

\section{INTRODUCTION}

Alluvial deltas are complex depositional systems of material fed by rivers into a standing body of water. Their stratigraphy is often used to infer changes in the water level and the wave energy of the basin as well as in the sediment supply of the channel that originated it. Further, much of the attention deserved by coarsegrained deltas partly arises from their potential as hydrocarbon and minerals reservoirs. If the standing body of water is caused by a dam, the rate at which sediment deposits within the impoundment and progrades towards the 
dam becomes crucial to foresee the lifetime of the reservoir: many reservoirs are nearly filled with sediment, and others are close to the end of their life-span (Evans et al., 2000).

Classical Gilbert-type deltas have delta fronts that, as they prograde into still water (sea, lake, reservoir, etc.), maintain a slope that is at, or not too far below, the angle of repose (Gilbert, 1890; Kleinhans, 2005; Muto et al., 2012). In these types of deltas, all sediment coming in settles on the topset and foreset, which might result in a delta that progrades, aggrades and gradually lowers the streamwise slope of the topset (Nemec, 1990).

As illustrated in Fig. 1 (based on Vanoni, 1975), deltas show a depositional structure composed of three different zones: (i) a delta topset, where the material entering into the system may be transferred to a prograding distributary plain; (ii) a foreset, also referred to as the lee surface, corresponding to the relatively steep face of the prograding delta, where the material being transported along the topset deposits after avalanching across the topsetforeset brinkpoint therefore making the delta prograde basinward; and finally (iii) a bottomset, i.e. a mild-slope delta toe deposit located downstream of the foreset, the material of which is finer than that forming the foreset (Jopling, 1965). Figure 1 shows the way in which a delta progrades within an impoundment. The respective average slopes of the topset and the foreset reflect the different dominant processes occurring within. The topset slope depends on external constraints, i.e. the sediment supply rate, water depth and sediment grain-size distribution, among others. In a Gilbert-type delta, however, the slope of the foreset remains close to the submerged angle of repose (Vanoni, 1975; Carling \& Glaister, 1987; Hotchkiss \& Parker, 1991; Kleinhans, 2002).

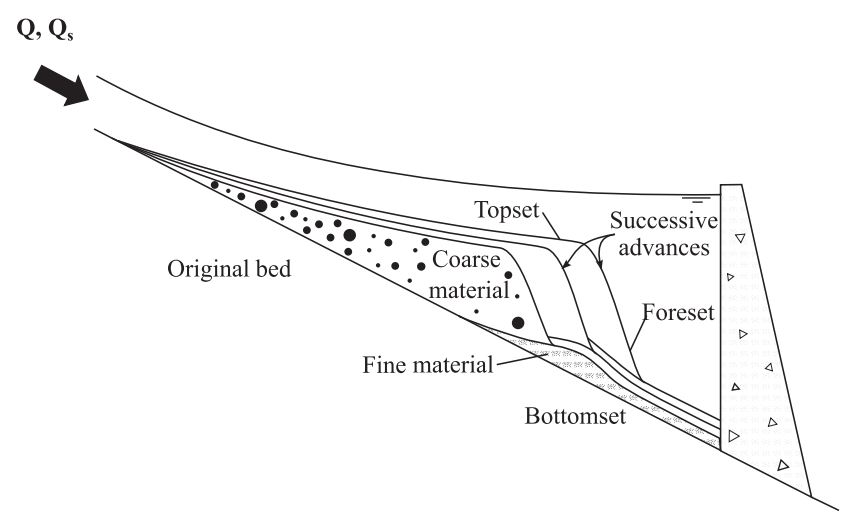

The modes by which sediment is moved in these three zones are dramatically different. While the topset area is associated with alluvial sediment transport processes, material is transported along the foreset by gravity-driven mechanisms. Sediment transported in suspension deposits either on the bottomset or on the foreset (individual material grains can be deposited at the foreset-bottomset break after being ejected from the foreset-topset brinkpoint). Although different processes dominate in each zone, all three areas constitute an integral and coexisting sedimentary structure (Nemec, 1990).

The sedimentary processes involved in Gilbert-type deltas have been studied widely by means of experimental analyses (Jopling, 1965; Hunter \& Kocurek, 1986; Seal et al., 1997; Kleinhans, 2005; Blom \& Kleinhans, 2006). Equivalent sedimentary processes along lee sides of dunes and isolated steps have also deserved attention (Allen, 1965; Hunter, 1985a; Blom \& Kleinhans, 2006). Bed material being transported either in suspension or as bedload can be deposited on the lee surface below the brinkpoint as flow separates downstream of it; the former can even be deposited further downstream in the bottomset (Jopling, 1965). Sediment is moved along the foreset as grain falls, grain flows and individual grains rolling down (Jopling, 1965; Hunter, 1985b; Carling \& Glaister, 1987). Grain fall refers to the process by which bed material settles from suspension onto the foreset or the bottomset. Bedload is deposited in the upper part of the foreset forming a wedge, the slope of which (static angle of repose) is steeper than the average foreset slope (dynamic angle of repose). Bed material accumulated in the top wedge periodically collapses and falls down along the lee face when its slope grows beyond the static angle of repose. This mechanism, called 'avalanching', consists of a grain
Fig. 1. Schematic diagram of bed profiles of a prograding Gilbert-type delta within an impoundment upstream of a dam (based on Vanoni, 1975). 
flow that is the main process responsible for emplacement of the foreset (Nemec, 1990). Grain flow is an intermittent process because some time is needed to build the oversteepened wedge (Allen, 1965, 1970; Hunter, 1985b). However, continuous 'avalanching' may occur when sediment supply exceeds a critical value (Hunter \& Kocurek, 1986; Nemec, 1990). The process by which the foreset is formed has been mathematically modelled by semi-theoretical approaches (Allen, 1970; Hunter, 1985b; Blom \& Parker, 2004; Blom \& Kleinhans, 2006; Blom et al., 2006) and by empirical approaches (Kleinhans, 2005). The semi-theoretical approach proposed by Blom \& Kleinhans (2006) has recently been included by Viparelli et al. $(2011,2014)$ in a morphodynamic model for Gilbert-type deltas.

Field examples of Gilbert-type deltas have been the subject of much previous study (Hunter, 1985a; Bornhold \& Prior, 1990; Sohn et al., 1997; Saito, 2011), including systems composed of a variety of grain-size distributions ranging from fine sand (Hunter, 1985a) to coarse sand and gravel (Saito, 2011) and even boulders (Bornhold \& Prior, 1990). Sorting processes associated with Gilbert-type deltas have also been studied experimentally. Jopling (1965) studied the particle paths transported in suspension downstream of the brinkpoint, and resulting patterns of deposition in the foreset, by conducting a set of experiments with sands and a sandgravel mixture. Hotchkiss (1989; see also Hotchkiss \& Parker, 1991), conducted experiments on prograding deltas using quasi-uniform lightweight material (crushed walnut shells). Cantelli et al. (2004) performed two experiments on delta progradation in a reservoir with uniform sand. These authors recorded delta evolution until the impoundment was completely filled. Kleinhans (2005) conducted a set of experiments on delta progradation with sediment mixtures, the aim of which was to study the grain sorting by grain flows on the foreset. The experiments allowed establishment of empirical expressions for dimensionless parameters characterizing sorting as functions of dimensionless delta properties.

Some researchers have studied bed sorting of sand-gravel mixtures in other, related sedimentary structures: Carling \& Glaister (1987) experimentally analysed bed sorting downstream of a negative step using bimodal sand-gravel mixtures. Bed material sorting in dunes has been studied by Kleinhans (2002) and Blom et al. (2003). This past research has identified different mechanisms affecting sorting at the lee face in Gilbert-type deltas and other steep slip-face bedforms: (i) slope failures (Bornhold \& Prior, 1990; Sohn et al., 1997); (ii) grain flows and avalanches (Bagnold, 1954; Allen, 1965, 1970; Jopling, 1965; Hunter, 1985a; Hunter \& Kocurek, 1986; Blom et al., 2003; Kleinhans, 2005); (iii) kinetic sieving on the lee face: the small particles in the grain flow dynamically percolate through the pores left by the coarse material resulting in an upward coarsening of the grain flow laminae thickness (Kleinhans, 2005); and (iv) individual grain falls (Allen, 1965; Jopling, 1965; Kleinhans, 2005). The interaction between sediment supply and wave action (Saito, 2011), as well as geometrical mechanisms caused by coarse protruding particles at the lee face and the temporal succession of gravity-driven flows (Nemec, 1990; Sohn et al., 1997), have been recognized as controlling factors of sediment sorting along lee faces. The major presence of coarse particles in the outer layer of grain flows has also been explained in terms of dispersive pressures caused by grain collisions in a mixture (Bagnold, 1954). A downward coarsening distribution of sediment along the lee face is the most typical grain-size profile in steep slope subaqueous bedforms and deltas, although some upward coarsening settings have also been documented (Jopling, 1965; Hunter, 1985a; Sohn et al., 1997).

The experiments performed by Jopling (1965) appear to be the first attempt to study the bed grain-size distribution within a delta deposit. Experiments carried out by Kleinhans (2005) have made a significant contribution to the knowledge of bed material size sorting created by prograding deltas.

The groundbreaking research of Kleinhans (2005) was focused on sorting processes on the delta foreset itself (sediment samples were extracted from the lee face). The present experimental research extends the scope of this work by considering both the vertical and horizontal structure of the entire deltaic deposit. This structure is characterized in terms of the spatial variation in the grain-size distribution of the sediment. Knowledge of the pattern of this spatial variation, along with the time evolution of the bed profiles of the topset/foreset as the delta progrades, allows a sorting function similar to that of Kleinhans (2005) to be back-calculated from measured stratigraphy. The present research thus offers a new methodology for inferring aspects of the morphodynamics of delta progradation from its stratigraphy. 


\section{DESCRIPTION OF THE EXPERIMENTAL SET-UP}

One experiment was carried out in a $12 \mathrm{~m}$ long and $0.60 \mathrm{~m}$ wide rectangular tilting flume. Sediment was placed over the horizontal, inerodible bed so as to make an antecedent deposit with a slope of $0.02 \mathrm{~m} \mathrm{~m}^{-1}$. The deltaic deposit prograding over this surface thus had a foreset height that increased as in time as it prograded over an ever-lower bed.

The bed material was composed of a sediment mixture with geometric mean size $D_{\mathrm{g}}=3.39 \mathrm{~mm}$ and geometric standard deviation $\sigma_{\mathrm{g}}=1 \cdot 8$. The specific gravity of the mixture was $2 \cdot 58$, the bed porosity was 0.35 (Viparelli et al., 2010a) and the size $D_{90}$ (such that $90 \%$ of the sediment is finer) was $7.83 \mathrm{~mm}$. This material was also employed as sediment supply from the channel inlet. A vertical dam was used to create an obstacle to the flow such that sediment supplied deposited in the impoundment upstream. The dam was located $9 \mathrm{~m}$ from the inlet of the flume. The dam height above the initial sediment bed was $15 \mathrm{~cm}$. A summary of the main features of the experiment can be found in Table 1. The experiment reported here was carried out in the same flume and using the same sediment as that of Viparelli et al. (2010a,b). Hence, the experiment was conducted using a setup that had been well-verified in advance. The experiments of Viparelli et al. (2010a) were performed for developing and validating a model of river aggradation/degradation due to differential bedload transport of sediment mixtures. Here, the focus is on the sorting that results as sediment is emplaced on a prograding foreset, which is driven by the longitudinal sorting of the sediment transported along the delta topset. The antecedent experiments of Cantelli et al. (2004) on incision into sandy deltaic deposits upon dam removal proved helpful in the design of the present experiment. Figure 2 shows the grain-size distribution of the mixture used during the experiment reported here. This distribution was used for emplacing an initial sediment bed, and was also used for the feed sediment.

Water discharge was measured with an electromagnetic flow meter attached to the pipe inlet. A valve was used to adjust the discharge to the desired value. Sediment was introduced at a constant rate by means of a sediment screwtype feeder. The sediment feeder was placed within the first $2 \mathrm{~m}$ of the flume ( $x=0$ to $2 \mathrm{~m}$ ). The sediment mixture used was introduced dry, into the upper box of the feeder. Water depths were measured at stations upstream of the dam $1 \mathrm{~m}$ apart. The closest and the furthest measurement stations from the dam are located at $x=8 \mathrm{~m}$ and $x=3 \mathrm{~m}$, respectively. Thus, water depth was registered at six stations upstream of the dam.

The flume upstream of the dam was uniformly filled with the mixture up to a depth of $0.1 \mathrm{~m}$ prior to the experiment. Sediment feed was commenced at the specified rate, and the water pumps were switched on to the specified discharges, all simultaneously. Water and sediment

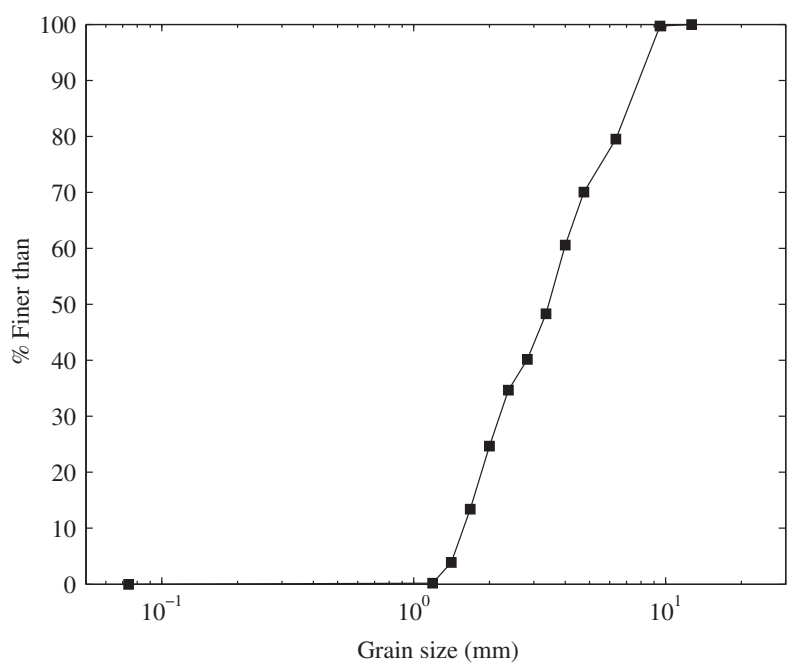

Fig. 2. Feed and initial (antecedent) bed grain-size distribution used in the experiment.

Table 1. Main characteristics of the experiment. $D_{\mathrm{g}, \mathrm{f}}$ and $\sigma_{\mathrm{g}, \mathrm{f}}$ are the geometric mean diameter and the geometric standard deviation of the sediment feed, respectively, $L_{\mathrm{f}}$ and $W_{\mathrm{f}}$ are the flume length and the flume width; $Q_{\mathrm{w}}$ and $Q_{\mathrm{s}}$ are the water and the sediment discharges; $S_{\mathrm{t}}$ and $S_{\mathrm{b}}$ are the topset and the initial bed slope, respectively, $H$ is the mean water depth above the topset and finally $H_{\mathrm{d}}$ and $C$ illustrate the range of the delta height and the celerity of the deltaic deposit registered during the experiment.

\begin{tabular}{llllllllllll}
\hline$D_{\mathrm{g}, \mathrm{f}}(\mathrm{mm})$ & $\sigma_{\mathrm{g}, \mathrm{f}}(-)$ & $L_{\mathrm{f}}(\mathrm{m})$ & $W_{\mathrm{f}}(\mathrm{m})$ & $Q_{\mathrm{w}}\left(\mathrm{m}^{3} \mathrm{sec}^{-1}\right)$ & $Q_{\mathrm{s}}\left(\mathrm{kg} \mathrm{sec}^{-1}\right)$ & $S_{\mathrm{t}}(-)$ & $S_{\mathrm{b}}(-)$ & $H(\mathrm{~m})$ & $H_{\mathrm{d}}(\mathrm{m})$ & $C\left(\mathrm{~cm} \mathrm{~min}^{-1}\right)$ \\
\hline 3.39 & 1.8 & 12 & 0.60 & $4.70 \times 10^{-2}$ & $1.33 \times 10^{-2}$ & 0.005 & 0.02 & 0.10 & 0.60 to & 0.135 & 0.52 to 0.81 \\
\hline
\end{tabular}


discharges were chosen so that a topset slope near $0.005 \mathrm{~m} \mathrm{~m}^{-1}$ evolved. The sediment feed rate was set to $1.33 \times 10^{-2} \mathrm{~kg} \mathrm{sec}^{-1}$, a value chosen so that impoundment filling would take place within a convenient amount of time. With this in mind and with the aid of previous experiments carried out with the same facility and sediment mixture (Viparelli et al., 2010a,b), water discharge was set equal to $47 \mathrm{l} \mathrm{sec}^{-1}$. Indeed, the selected water discharge, sediment discharge and grain-size distribution, correspond to an equilibrium bed slope of $0.005 \mathrm{~m} \mathrm{~m}^{-1}$ (Viparelli et al., 2010a,b). Bed profiles were measured with the aid of four ultrasonic transducer probes (described in Wong et al., 2007), located at transverse distances $13.5 \mathrm{~cm}, 24.5 \mathrm{~cm}$, $35.5 \mathrm{~cm}$ and $46.5 \mathrm{~cm}$ with respect to one side of the flume, attached to a carriage. Four streamwise bed profiles could thus be simultaneously measured just by moving the carriage along the flume. Long profile measurements spanned from $x=3 \mathrm{~m}$ in the upstream end (i.e. $1 \mathrm{~m}$ downstream of the feeder) to a distance between $0.5 \mathrm{~m}$ and $1 \mathrm{~m}$ downstream of the foresetbottomset break. This procedure was followed, because the experiment was conducted in the absence of sediment transported in suspension, which means that sediment was deposited along the topset or the foreset without settling on the bottomset. The elevations of the topset were taken at a $0.2 \mathrm{~m}$ resolution. Node spacing along the foreset slopes was decreased to $0.02 \mathrm{~m}$. The spatial resolution of the measurements was gradually reduced to $0.1 \mathrm{~m}$ and $0.05 \mathrm{~m}$ in cases where it was observed that the topset approached the foreset slope. After each bed profile measurement, the flume was drained in order to video record the position of the delta front. To continue the run, the flume was backfilled by means of two hoses (if the flume had been filled by its inlet, water would have eroded the delta front).

Sediment samples of the deltaic deposit were taken once the experiment was finished. Samples were extracted with a metallic box $30 \mathrm{~cm}$ high, $10 \mathrm{~cm}$ wide and $15 \mathrm{~cm}$ long. This box has been previously used by Blom et al. (2003), and is documented therein. The box was manually driven into the deposit, and then extracted with the material inside it. The delta was destroyed after the sediment sampling (see Fig. 3). Samples were extracted from six cross-sections of the deposit, equally spaced $1 \mathrm{~m}$ apart (from $x=3.5$ to $8.5 \mathrm{~m}$, which correspond to the last $5.5 \mathrm{~m}$ of the flume upstream of the dam). Two samples were extracted from each cross-section, i.e. one at each side of the bed. The sediment contained in the box was divided into $2 \mathrm{~cm}$ thick slices, each of which was sieved independently. The deepest samples corresponded to a depth of $5 \mathrm{~cm}$ and were extracted from the initial bed layer of $0.1 \mathrm{~m}$ deep. A total of 79 samples were analysed.

The run was ended when the toe of the foreset reached the dam. The experiment was repeated twice to check for consistency. Details of the experiment can be found in Ferrer-Boix (2011).

\section{EXPERIMENTAL RESULTS}

Experimental results obtained from the run on delta progradation are shown below. One run was used to collect data, while the other one was used to verify the delta progradation pattern. The experiment was used to analyse how the delta fills the impoundment as it approaches the dam and how bed material is sorted within the deposit.

\section{Delta evolution}

As water and sediment approach the dam, water velocity slows and bed material deposits, resulting in an aggrading bed profile. In general, bed mate-

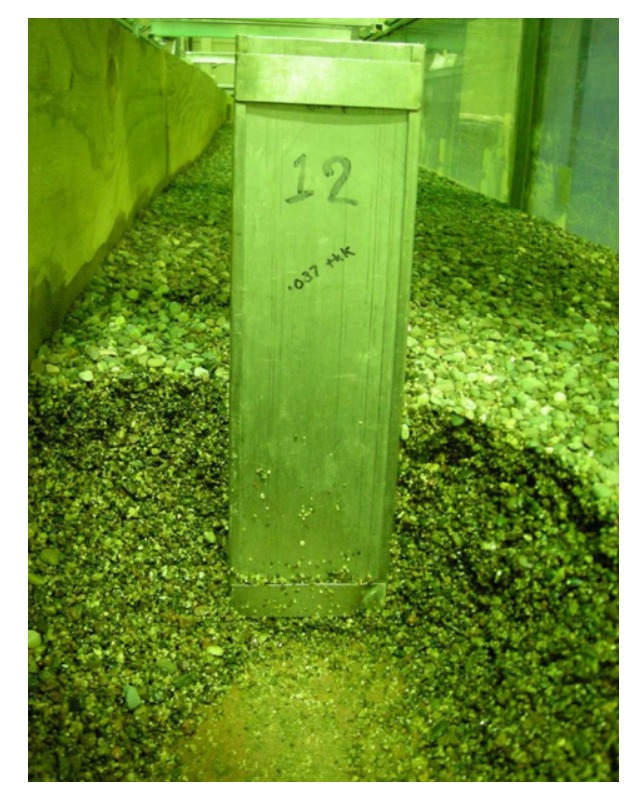

Fig. 3. Photograph illustrating the excavation of material for sampling of delta material as well as the sediment sampling device (used by Blom et al., 2003 and Viparelli et al., 2010a,b). 
rial is deposited both on topsets, causing bed aggradation, and on foresets, causing progradation towards the dam (Hotchkiss \& Parker, 1991).

Figure 4 plots the delta advance towards the dam at different times until complete filling of the impoundment after approximately $10.5 \mathrm{~h}$. Data obtained by the four probes have been averaged in order to obtain one profile of the delta at each time. All profiles show small irregularities that are thought to be bars that were too subtle to be distinguished by sight. Figure 5 shows three positions of the delta foreset during one of the two runs on delta progradation.

It can be seen in Fig. 4 that if the first profile (for which there are only four points to calculate the slope) is omitted, the topset slope changes little in time. The second profile already exhibits a topset slope of $0.0049 \mathrm{~m} \mathrm{~m}^{-1}$, i.e. identical to the last profile at $t=625 \mathrm{~min}$, which was obtained with 34 points $\left(R^{2}=0.95\right)$. This slope was also nearly equal to the equilibrium value associated with the water discharge, sediment feed rate and sediment size distribution (Viparelli et al., 2010a, b). Figure 6 illustrates the changes in bed elevation $\Delta z$ of the topset between consecutive long profiles. Topset aggraded until $t=359 \mathrm{~min}$ and degraded from this time onwards. Maximum mean topset aggradation between $t=138 \mathrm{~min}$ and $t=238 \mathrm{~min}$ was $4.2 \mathrm{~mm}(2.8 \mathrm{~mm}$ between $t=238 \mathrm{~min}$ and $359 \mathrm{~min})$. Mean topset degradation was $1.1 \mathrm{~mm}$ from $t=359$ to $510 \mathrm{~mm}$ $(1.7 \mathrm{~mm}$ from $t=510$ to $625 \mathrm{~mm})$. Thus, after $t=359 \mathrm{~min}$, there is no longer significant vertical storage of material due to aggradation, and the delta grows by means of sediment emplacement in the foreset as it progrades downstream (accompanied by little degradation of the delta topset: $2.8 \mathrm{~mm}$ in the last $4.4 \mathrm{~h}$ of the run). The inset plot at the top right of Fig. 6 illustrates the elevation of the delta and its height at the brinkpoint ( $z_{\mathrm{bp}}$ and $H_{\mathrm{d}, \mathrm{bp}}$, respectively). Under conditions of a constant base level, material emplaced in the foreset decreases the slope of the delta topset as it progrades downstream, thus causing a reduction in the sediment transport capacity in the downstream direction. This configuration leads to an upward-concave profile if the width of the topset is maintained uniform - some changes in the curvature may arise driven by downstream variations of the surface grain-size distribution

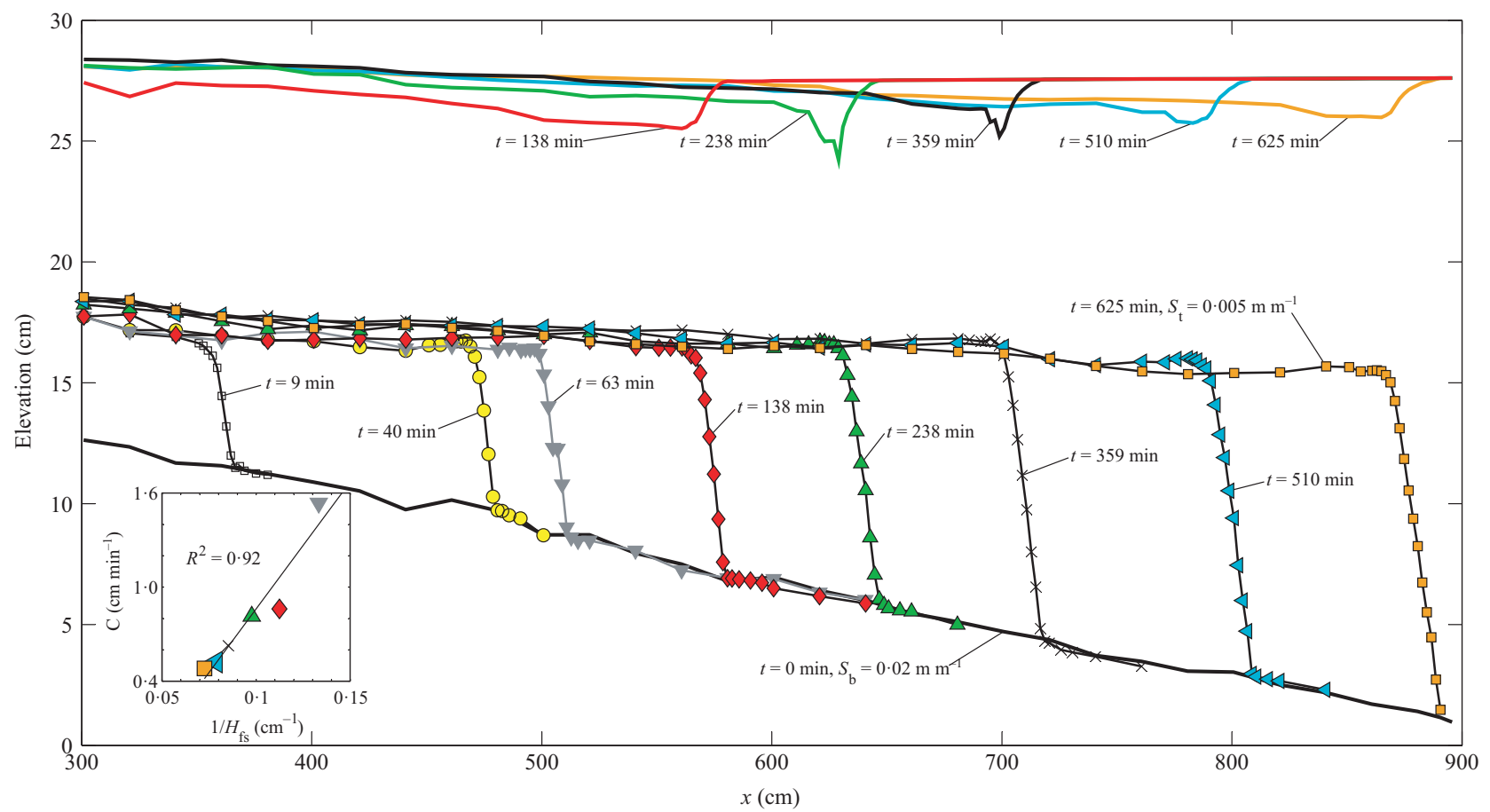

Fig. 4. Delta profiles at different times. Values have been obtained by averaging from the four transducer probes located at each cross-section. In the bottom-left is a plot of the delta celerity (C) versus the inverse of delta height $\left(1 / H_{\mathrm{fs}}\right)$. The markers shown in the delta profiles in the main plot have been used in the celerity-height plot. Colour lines are the water surface profiles obtained with the hydraulic model for the delta profiles registered at $t=138 \mathrm{~min}, 238 \mathrm{~min}, 359 \mathrm{~min}, 510 \mathrm{~min}$ and $625 \mathrm{~min}$. The colour of the line matches the colour of the marker for a pair of water surface and bed profiles, respectively. 
(Ferrer-Boix et al., 2014). Concavity of each topset long profile has been examined by fitting potential curves. Results of the interpolation show that all long profiles are slightly upwardconcave. Topset profiles exhibit low values of the mean curvature (ranging between $9.9 \times 10^{-4} \mathrm{~m}^{-1}$ and $1.5 \times 10^{-4} \mathrm{~m}^{-1}$ ) with no significant differences between aggrading and degrading profiles.
The foreset slope is close to the angle of repose. The average foreset slope is $34^{\circ}$. This value corresponds with the prediction of Carling \& Glaister (1987), i.e. a foreset slope of 31 to $34^{\circ}$ for a sand content in the sediment ranging from 20 to $60 \%$. The fraction of sand in the mixture used in this experiment was $24 \cdot 7 \%$.
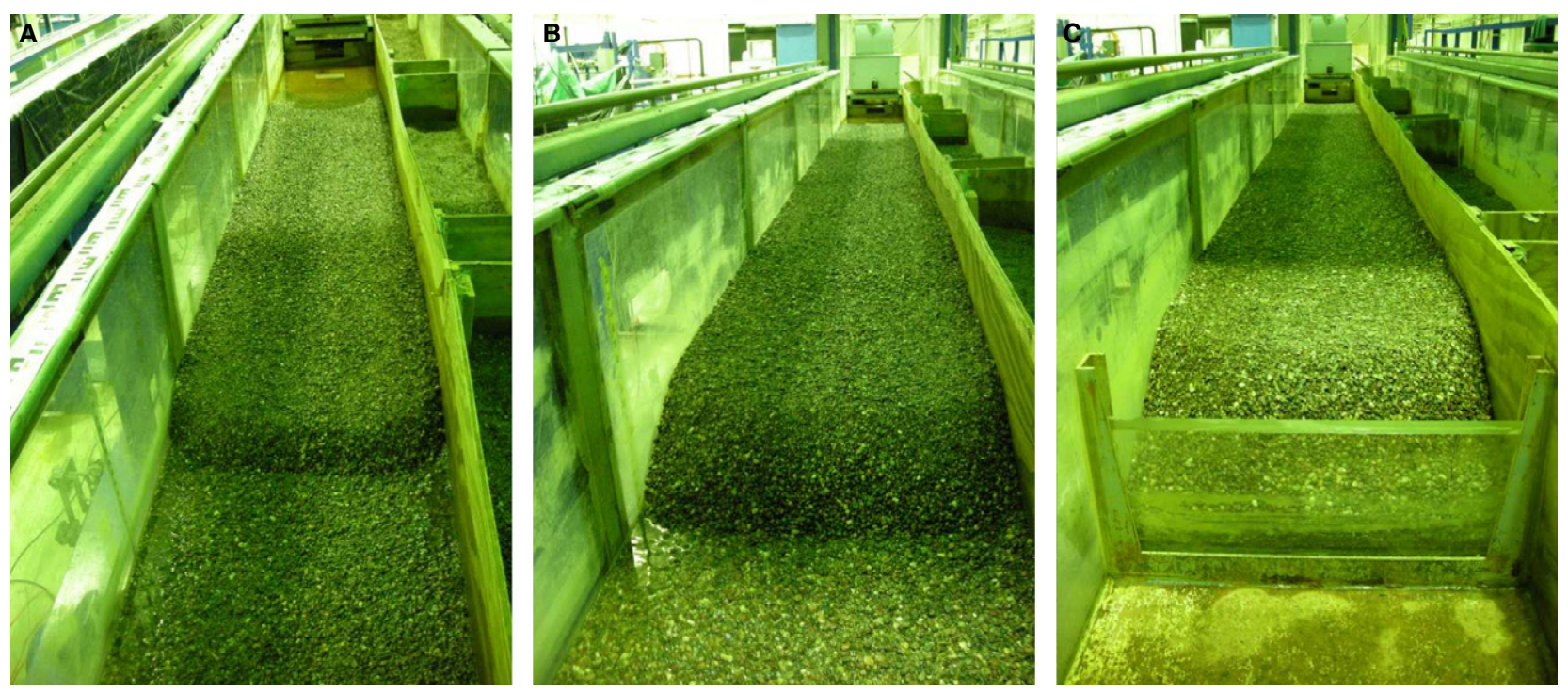

Fig. 5. Three front views of the prograding delta at different times: $40 \mathrm{~min}(\mathrm{~A}), 510 \mathrm{~min}(\mathrm{~B})$ and $625 \mathrm{~min}(\mathrm{C})$.

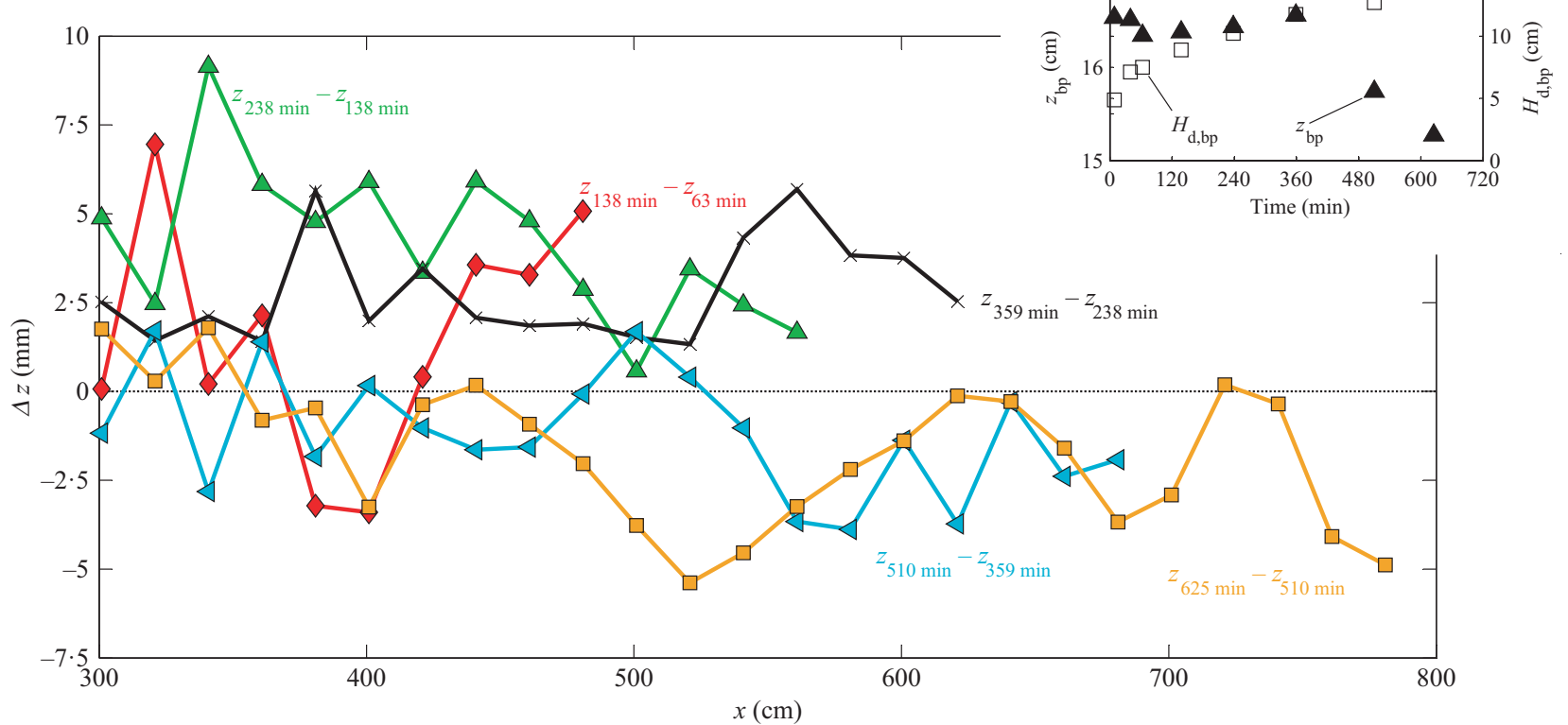

Fig. 6. Changes in bed elevation of the topset between consecutive long profiles after $t=63 \mathrm{~min}$. The inset plot illustrates the temporal evolution of the bed elevation (black triangles) and the delta height (white squares) at the brinkpoint. 
Delta progradation celerities were computed from long profiles in Fig. 4. The delta front position is here defined as the topset-foreset brinkpoint. It was found that front celerity follows a decaying relationship with elapsed time: the larger the time the slower the delta celerity, confirming the mathematical findings of a prograding delta analysed by, for example, Lorenzo-Trueba \& Voller (2010).

There are two reasons why delta celerity should decrease in time. Even under conditions of constant base level (downstream water surface elevation in the present case) and progradation over a horizontal bed, celerity decreases in time, because under aggrading topset conditions, a loss of sediment due to the emplacement of an ever-longer topset reduces the sediment supply to the brinkpoint. In the case of the present experiment, however, the antecedent bed had a slope of $0.02 \mathrm{~m} \mathrm{~m}^{-1}$, so that antecedent bed elevation declined. This condition forced the height of the foreset to increase as it migrated downstream. For the same amount of sediment delivered to the brinkpoint, a higher foreset implies a lower progradation speed. Because the topset slightly aggraded during the first six hours of run and degraded afterwards, it was this latter effect that dominated decreasing the celerity with time.

\section{Bed material sorting}

Figure 7 shows the geometric mean grain-size distribution within the delta deposit. Initial and final bed profiles have been included. Expressing any grain size $D$ in the $\psi$-scale such that:

$$
D=2^{\psi}
$$

The geometric mean diameter $D_{\mathrm{g}}$ is calculated as:

$$
\psi_{\mathrm{g}}=\sum_{i=1}^{M} \psi_{\mathrm{mi}} f_{i} \text { and } D_{\mathrm{g}}=2^{\psi \mathrm{g}}
$$

where $\psi_{\mathrm{mi}}$ is the centre of each grain class in the $\psi$-scale, $f_{i}$ are the sediment fractions of each grain class being $M$ the number of grain classes of the mixture. The geometric standard deviation of the samples $\sigma_{\mathrm{g}}$ is obtained as:

$$
\sigma^{2}=\sum_{i=1}^{M}\left(\psi_{\mathrm{mi}}-\psi_{\mathrm{g}}\right)^{2} f_{i} \text { and } \sigma_{\mathrm{g}}=2^{\sigma}
$$

Four different layers can be observed (from top to the bottom) in Fig. 7:

1 In the topmost layer, mean grain size is close to that of the feed material $(3.39 \mathrm{~mm})$. However, some fining is observed within this layer. Sedi-

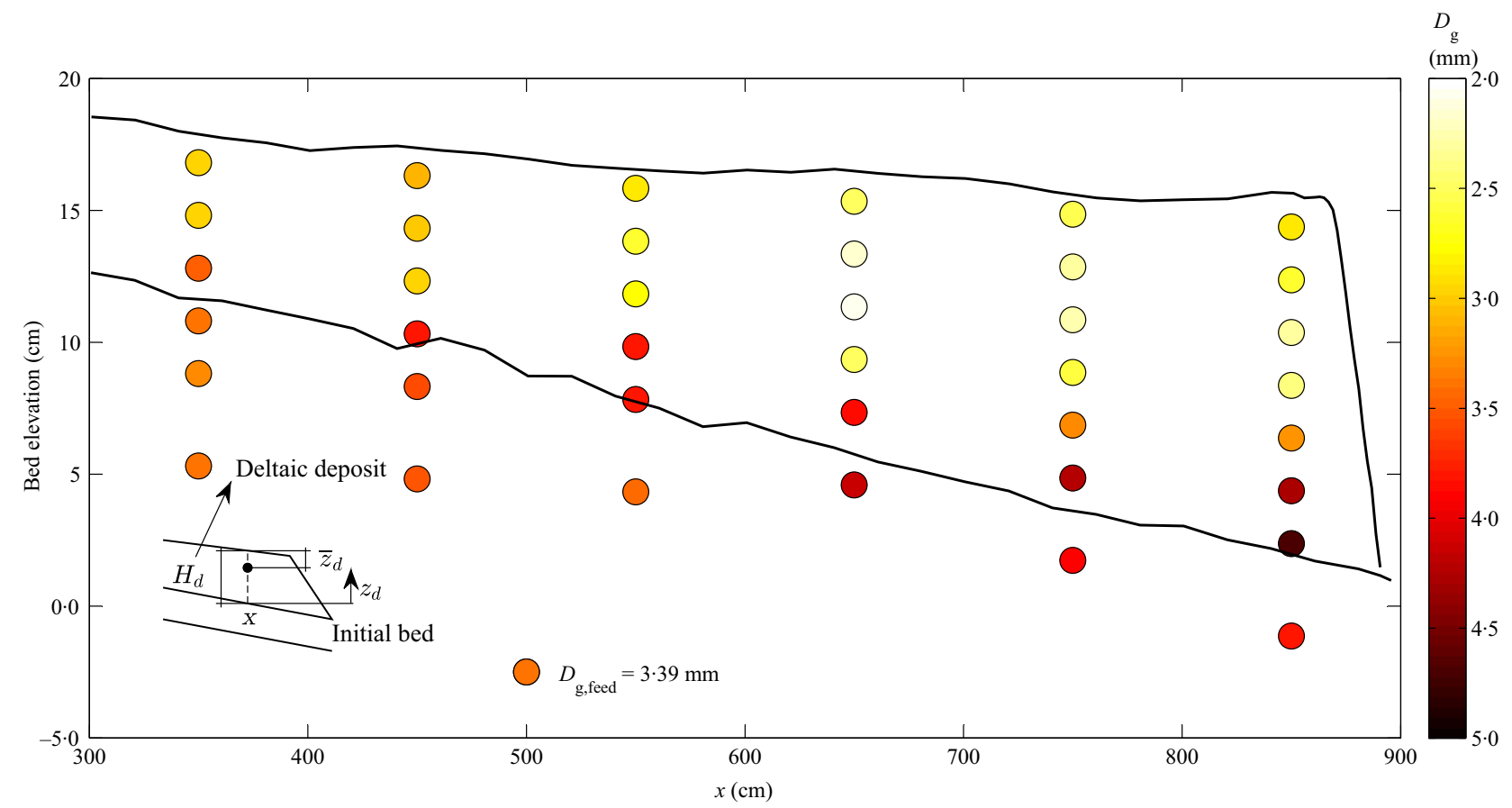

Fig. 7. Geometric mean diameter within the deltaic deposit and in the initial (antecedent) sediment. 
ment in the topset exhibited modest downstream fining; this is in agreement with Kleinhans (2005) which observed downstream fining of the topset for slopes smaller than 0.05.

2 Below that layer, there was a much finer and thicker layer.

3 Between the above layer and the initial (antecedent) bed, which corresponds to the base of the deposit emplaced by this experiment, material was coarser than the feed sediment.

4 The sediment below the initial bed had a grain-size distribution that was chosen to be approximately the same as the sediment feed.

The fining of the top layer in the downstream direction (Fig. 7) is clearly discerned when compared with the fourth layer, for example the antecedent bed. Also, it is worth noting that the surface samples are finer than the mixture, which might be related to the thickness of the samples (in this case $2 \mathrm{~cm}$ thick, i.e. more than two times the $D_{90}$ of the mixture). Thus, textures of the uppermost sediment samples are representative of the surface of the delta and the upper part of the deltaic deposit. Except for the sample at channel station $x=550 \mathrm{~cm}$, sediment samples below the surface are slightly coarser than the material below. This may reflect the fact that coarse material near the wall of the sampling metallic box is pushed down as the latter is driven in the deltaic deposit (Blom et al., 2003).

The bed material within the entire deltaic deposit can be characterized by comparison with the grain-size distribution of the sediment feed. Grain-size distribution variations are analysed by means of the grain size such that $16 \%$ of the mixture is finer $D_{16}$, the geometric mean diameter $D_{\mathrm{g}}$ and the grain size such that $90 \%$ of the mixture is finer $D_{90}$.

To this end, let $\psi_{x, z}$ denote grain size such that $x$ denotes, for example 16 , g or 90 at a particular depth within the deposit $z$, and $\psi_{x, f}$ denote corresponding values of $\psi$ for the feed. The deviation of size $\psi_{x, z}$ from the corresponding value for the feed sediment, can then be expressed in terms of the parameter $\psi_{x, Z}^{*}$, where:

$$
\psi_{x, z}^{*}=\psi_{x, z}-\psi_{x, f}
$$

Introducing the definition of $\psi$ from Eq. 1 into Eq. 4 the following ratio, analogous to that above but expressed in terms of the diameter for the given value of $x$ is obtained by:

$$
D_{x, z}^{*}=\frac{D_{x, Z}}{D_{x, f}}
$$

Values of $\psi_{x, z}^{*}$ greater than 0 indicate a material that is coarser than the feed. The dimensionless depth at which the sample has been extracted $z_{\mathrm{d}}^{*}$ is defined as the ratio between the vertical coordinate $z_{\mathrm{d}}$ measured relative to the initial bed height, at which the sample is collected, and the thickness of the delta at the sampling point, $H_{\mathrm{d}}$ :

$$
z_{\mathrm{d}}^{*}=\frac{z_{\mathrm{d}}}{H_{\mathrm{d}}}
$$

Hence, values of the dimensionless depth $z_{\mathrm{d}}^{*}$ greater than 0 indicate samples taken from the delta deposit, whereas values of $z_{\mathrm{d}}^{*}$ less than 0 indicate samples extracted from the original bed.

Patterns of vertical sorting of the delta material are shown in Fig. 8, in which the left panel (Fig. 8A) corresponds to the evolution of the geometric mean diameter $D_{\mathrm{g}}$, the middle panel (Fig. $8 \mathrm{~B}$ ) corresponds to $D_{16}$ and the right panel (Fig. 8C) corresponds to $D_{90}$, all expressed in terms of expression (4). The vertical axis is the dimensionless depth $z_{\mathrm{d}}^{*}$. In all three panels, the horizontal axis ranges between $\psi_{x}^{*}=[-1,1]$, i.e. $\psi_{x, z}=\psi_{x, f} \pm 1$, which corresponds to diameter variation within the range $\left[(1 / 2) D_{X}, 2 D_{X}\right]$. Each panel contains six lines, corresponding to the six locations where samples were taken, see Fig. 7. Each point of these lines represents the value of $\psi_{x}^{*}$ at each sampling point within the vertical of the deposit, expressed in dimensionless form $z_{d}^{*}$ (Eq. 6). The different curves in the panels show the vertical stratigraphy of the deposit at distinct cross-sections, which are identified by delta height $H_{\mathrm{d}}$ (which increases downstream, as shown in Figs 4 and 8) and the streamwise distance $x$ at which the samples were extracted. All samples within the deltaic deposit were $2 \mathrm{~cm}$ thick; the number of sampling points at each streamwise location increased downstream in correspondence with increasing delta height (see also Fig. 4).

Referring to the geometric mean diameter (Fig. 8A), it is observed that all samples extracted from different locations of the delta deposit exhibit the same $S$-type pattern in the vertical. These types of curves have been qualitatively described as examples of sorting in bedforms under no suspended sediment, with 
armouring on the surface and grain flows composed primarily of gravel (Kleinhans, 2004). At the top of the curve $\left(z_{\mathrm{d}}^{*}=1\right), \psi_{\mathrm{g}}^{*}$ is close to zero, implying a geometric mean size close to that of the feed material. Geometric mean grain size diminishes downwards until reaching a minimum value at a depth close to the half of the delta height $\left(z_{\mathrm{d}}^{*}=0 \cdot 5\right)$. Below this point, diameters begin to increase until they attain a maximum value at the bottom of the deposit $\left(z_{d}^{*}=0\right)$. Bottom layer coarsening reaches values of $\psi$ that are almost 50\% larger than the feed (41\% larger values in terms of grain size $D$ ) at locations proximal to the dam. Samples deeper than those located at the bottom of the delta are close to 0 , meaning that, as expected, the antecedent bed has the same grain-size distribution as the feed sediment. The averaging inherent to the sampling technique is the reason why the uppermost samples of the initial bed $\left(z_{d}^{*}<0\right)$ are slightly coarser than the feed material.

The $16 \%$ percentile vertical variations of $\psi_{16}^{*}$ in Fig. 8B exhibit the same pattern as discussed above for the geometric mean diameter. It can be seen that there is less fining in the top half of the delta deposit compared to $\psi_{\mathrm{g}}^{*}$, and more coarsening in the bottom half. This behaviour differs from that observed for the $90 \%$ percentile in Fig. 8C: there is no significant coarsening of $\psi_{90}^{*}$ at the delta base, but fining within the delta deposit reaches almost $50 \%$ of the value of $D_{90}$ of the feed. This is because $\psi_{16}^{*}$ and $\psi_{90}^{*}$ account, approximately, for the lower and the upper boundaries of the grain-size distribution, respectively.

Figure 9 is a lateral view of the delta deposit at longitudinal coordinate $x=5 \mathrm{~m}$ (i.e. $4 \mathrm{~m}$ upstream of the dam). Downward coarsening within the delta is clearly seen: its bottom layer (above the horizontal line) is much coarser than the original bed (which has the same grain-size distribution as the sediment feed), as well as the layers above.

According to Fig. 8A, there is a positive gradient in the mean grain size between the middle of the delta height $\left(z_{\mathrm{d}}^{*}=0.5\right)$ and the bottom $\left(z_{d}^{*}=0\right)$. This grading 'intensity' can be quantified with the aid of the following expressions. Let $\bar{z}_{\mathrm{d}}$ define a downward dimensionless coordinate:

$$
\bar{z}_{\mathrm{d}}=1-z_{\mathrm{d}}^{*}
$$

A sketch of the delta sample showing the definition of $\bar{z}_{\mathrm{d}}$ has been included in Fig. 7. The vertical dimensionless gradients of $\psi_{\mathrm{g}}^{*}$ (Fig. 8A) are approximated by central finite differences as follows:

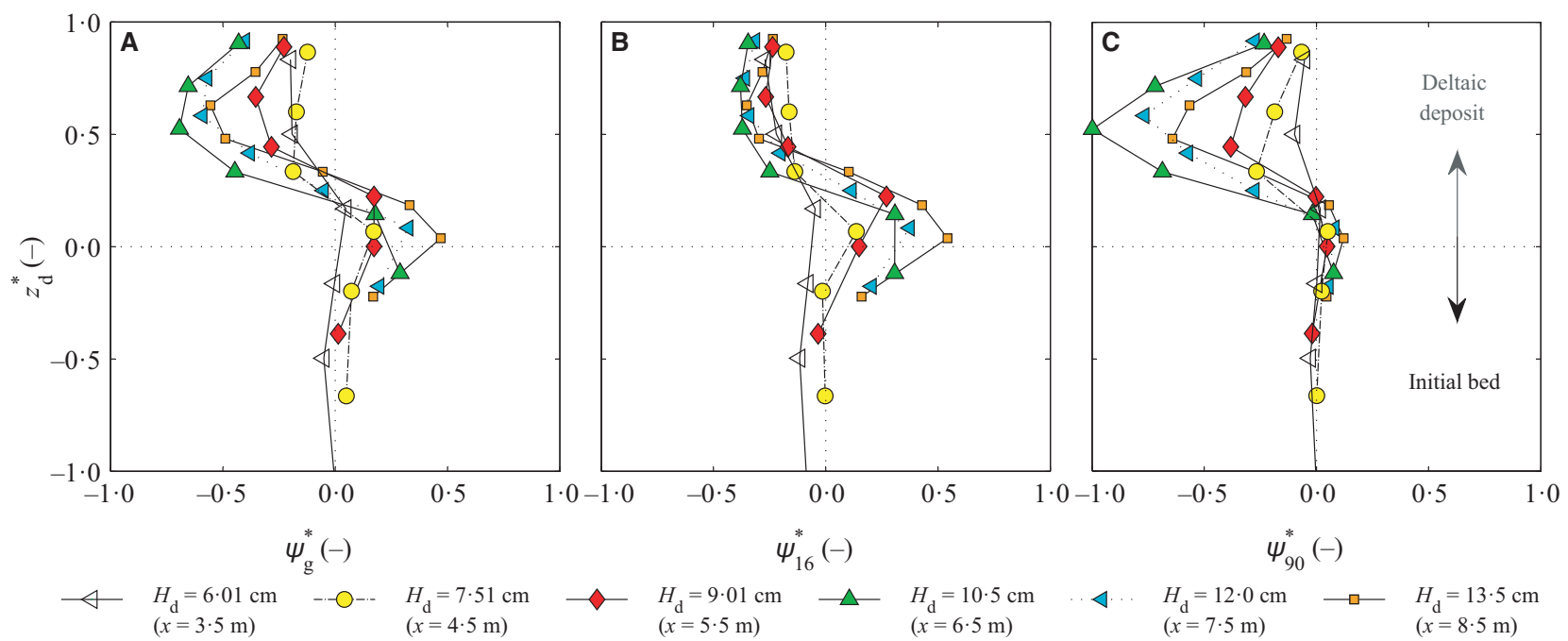

Fig. 8. Vertical sorting at different locations of the delta in terms of geometric mean diameter (left) and percentiles corresponding to $16 \%$ (centre) and $90 \%$ (right). There are six lines per panel. Each line plots the values of $\psi_{\mathrm{g}}$ (or $\psi_{16}$ or $\psi_{90}$ ) at the six locations where the samples were taken, ordered as measured from the inlet so that the most upstream sample is at $x=3.5 \mathrm{~m}$. and the most downstream sample is at $x=8.5 \mathrm{~m}$. (Note that the dam is located at $x=9 \mathrm{~m}$.) Each point of these lines represents the value of $\psi_{x}^{*}$ at each sampling point within the vertical of the deposit, the latter expressed in dimensionless form $z_{d}^{*}$. The value of $H_{\mathrm{d}}$ indicates the height of the delta at each location (which increases linearly in the downstream direction: see Fig. 10). 


$$
\frac{d \psi_{\mathrm{g}}^{*}}{d \bar{z}_{\mathrm{d}}} \cong \frac{\psi_{\mathrm{g}, z+1}^{*}-\psi_{\mathrm{g}, z-1}^{*}}{\bar{z}_{\mathrm{d}, \mathrm{z}+1}-\bar{z}_{\mathrm{d}, z-1}}
$$

The maximum value of this gradient $\left(d \psi_{\mathrm{g}} / d \bar{z}_{\mathrm{d}}\right)_{\max }$, which herein is called the grading intensity, is located between $z_{\mathrm{d}}^{*}=0.25$ and 0.5 . Figure 10 plots the maximum gradient as a function of the dimensionless length of the delta $x_{d}^{*}=x / L$, where $L$ denotes the distance between the feeder and the dam and $x$ is measured relative to the position of the feeder. The small inset panel illustrates the linear variation in delta

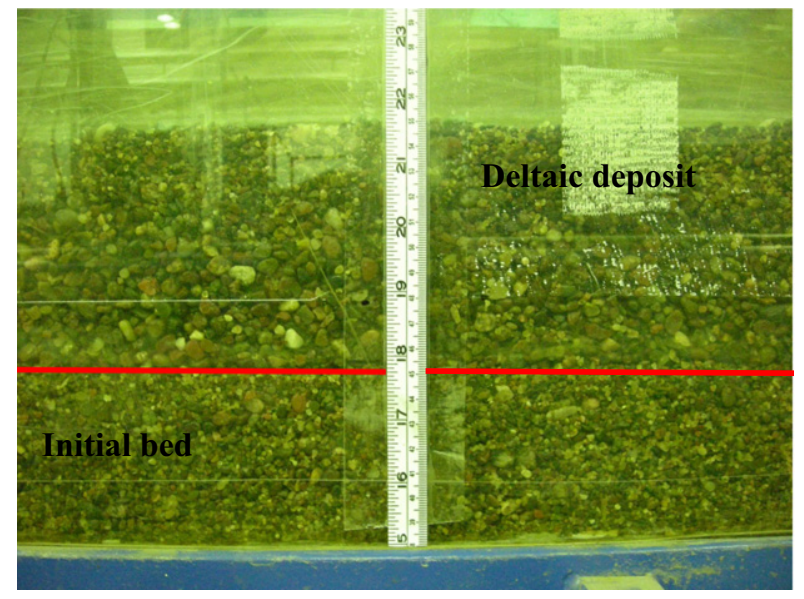

Fig. 9. Lateral view of the delta during the experiment. Water flows from left to right. The red line denotes the interface between the deposit and the antecedent sediment below. height $H_{\mathrm{d}}$ with the streamwise distance $x_{d}^{*}$, and thus $x$. Figure 10 clearly shows that there is a strong correlation between downstream distance in the delta and the vertical grading intensity, which means that, given the linear increase of the delta height with $x$, there is in fact a strong positive correlation between grading intensity and delta height.

Figure 8 shows a weak downstream fining of the delta grain-size distribution for the material in the top layer $\left(z_{\mathrm{d}}^{*}=1\right)$. Downstream sorting of the bottom layer is analysed in Fig. 11, which was obtained by averaging the corresponding values shown in Fig. 8 of the geometric mean diameter $\psi_{\mathrm{g}}^{*}$ (Fig. 11A), 16\% size $\psi_{16}^{*}$ (Fig. 11B) and $90 \%$ size $\psi_{90}^{*}$ (Fig. 11C), within the bottom layer $\left(z_{\mathrm{d}}^{*}=[0 \cdot 0-0 \cdot 2]\right)$. Downstream coarsening is clearly observed in all three plots. Moreover, the finer the reference diameter $\psi_{x}^{*}$, the greater the amount of coarsening. As noted before, this pattern is partly constrained by the lower and upper limits of the grain-size distribution. On the other hand, the feed material has been used for normalization of the vertical samples extracted from the deposit (Eqs 4 and 5). This material is coarser than the actual sediment transport rate over the brinkpoint, because some downstream fining has been noticed in the top layer. This normalization process might have contributed to an overestimation of the fining of the $D_{90}$ in the central part of the deposit and an underestimation of the coarsening of the $D_{90}$ in

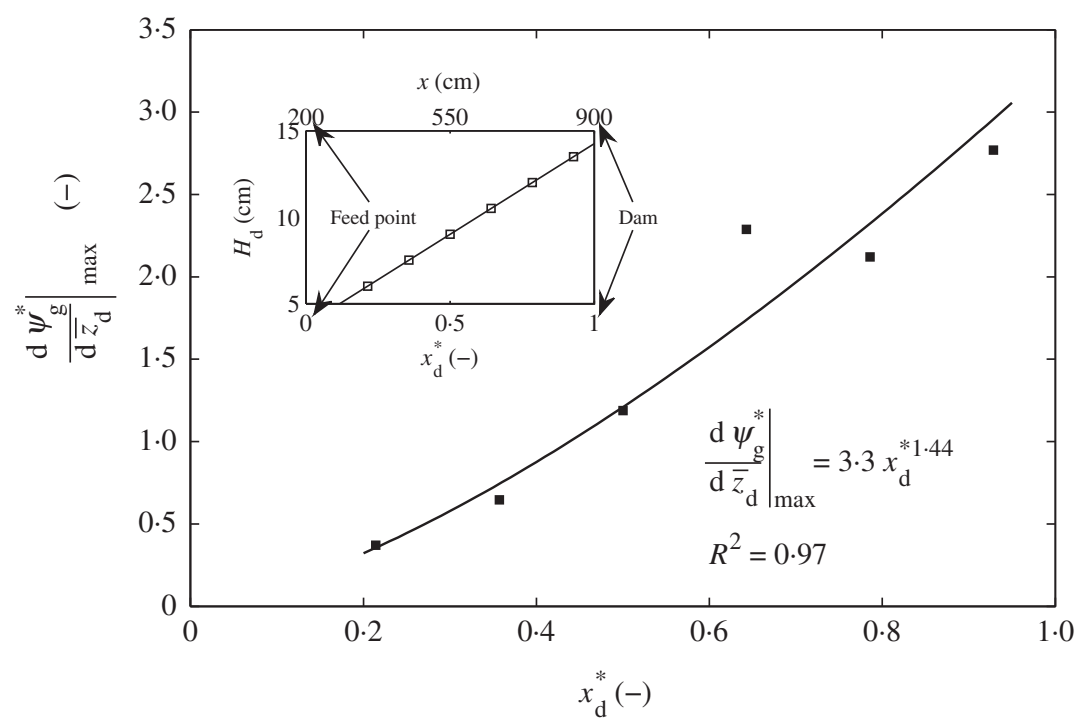

Fig. 10. Maximum gradient $\left(d \psi_{\mathrm{g}} / d \bar{z}_{\mathrm{d}}\right)_{\max }$ of the sorting material of the geometric mean diameter versus streamwise distance $x_{d}^{*}$. Inset plot shows the linear relation of the delta height $H_{\mathrm{d}}$ with the dimensionless streamwise coordinate. 

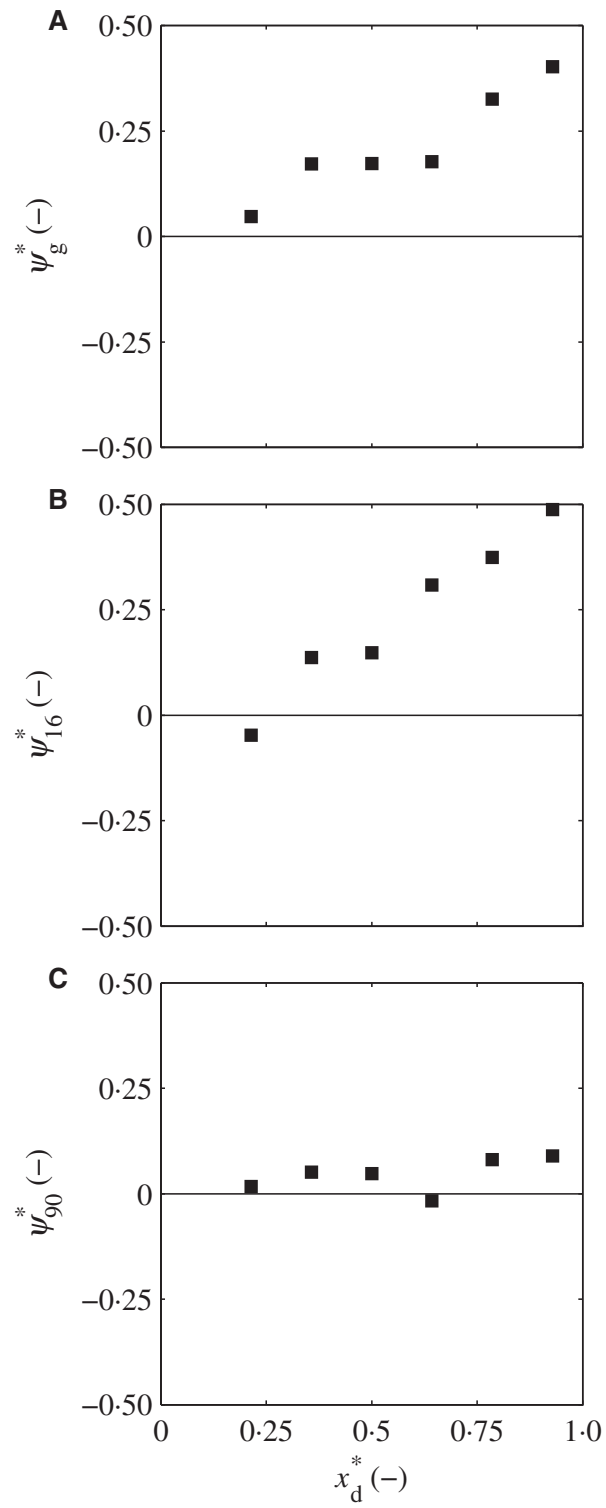

Fig. 11. Longitudinal sorting of the bed material within the bottom layer in terms of the geometric mean diameter $\psi_{\mathrm{g}}^{*}(\mathrm{~A})$, the sizes $\psi_{16}^{*}(\mathrm{~B})$ and $\psi_{90}^{*}(\mathrm{C})$.

the bottom layer (Fig. 8C). Finally, the variable density of sediment samples, especially in the verticals at $x=350 \mathrm{~cm}$ and $450 \mathrm{~cm}$ might have introduced an additional sorting in the bottom layer in the longitudinal direction.

A normalized standard deviation of grain-size distribution of a sample is defined here as $\sigma_{\mathrm{g}}^{*}$, where:

$$
\sigma_{\mathrm{g}}^{*}=\frac{\sigma_{\mathrm{g}, z}}{\sigma_{\mathrm{g}, f}}
$$

where, again, $f$ stands for the fed material and $z$ for elevation. Thus, $\sigma_{\mathrm{g}, \mathrm{z}}$ is the geometric stan-

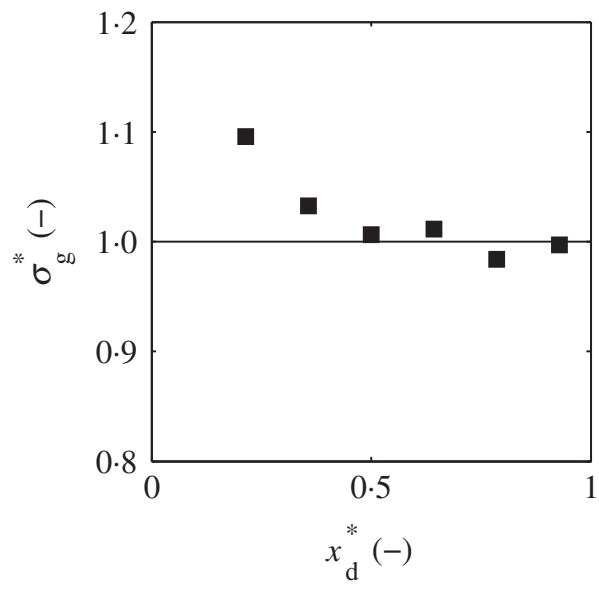

Fig. 12. Longitudinal variation of the geometric standard deviation $\sigma_{\mathrm{g}}^{*}$ within the upper layer of the deposit.

dard deviation of the deposit at elevation $z$ and $\sigma_{\mathrm{g}, \mathrm{f}}$ is the geometric standard deviation of the feed material. This parameter enables discussion of the patterns of sorting in the deposit. Values of $\sigma_{\mathrm{g}}^{*}$ greater than 1 mean that the grain-size distribution is more poorly sorted than the sediment feed. Figure 12 summarizes the downstream variation of $\sigma_{\mathrm{g}}^{*}$ as computed from the upper layer of the delta, i.e. the range $z_{d}^{*}=\left[0 \cdot 8^{-}\right.$ 1.0]. Within the upper layer $\sigma_{\mathrm{g}}^{*}$ diminishes as it moves downstream, demonstrating selective transport along the topset, with a wider range of sizes upstream and a narrower range downstream.

The process of sediment deposition on the foreset consists of repeated cycles of avalanches. Coarser material is initially deposited just below the break between the topset and the foreset, forming a steeper slope than the angle of repose. This material wedge eventually avalanches down the lee surface dragging finer material accumulated further below the topset-foreset break. The less volume of material involved, the more efficient the sorting process (Kleinhans, 2004). The avalanche generally results in preferential motion of the coarser material to the base of the foreset. Various sorting mechanisms occur during this material displacement (Kleinhans, 2002), but what is important here is that the higher the delta, the higher number of avalanches (because, for a given sediment transport rate, the greater the delta height, the more time required to fill the entire height of the delta to make it prograde). Kleinhans (2005) quantified this by introducing a coefficient $A^{*}$ which was defined as a dimensionless grain flow number: $A^{*}=R g h_{\mathrm{g}} C^{-2}$ where $R$ is the submerged specific 
gravity of the sediment, $g$ is the acceleration of gravity, $h_{\mathrm{g}}$ is the thickness of the grain flows and $C$ is the celerity at which the delta progrades. It is seen that for a given grain flow thickness $h_{\mathrm{g}}, A^{*}$ increases as the height of the delta celerity decreases. Because delta celerity is inversely proportional to the delta height (see bottom-left inset in Fig. 4), the dimensionless number of grain-flow events scales with the delta height. An increasing number of avalanches of material originated at the topset-foreset brinkpoint fall down the lee face of the delta preferentially dragging coarser particles along the foreset towards the bottom layer of the deltaic deposit. In addition, a thicker foreset prompts better grain separation as the sediment avalanches, so preferentially moving coarser material to the base of the delta. Note that the maximum grading intensity is located at $z_{\mathrm{d}}^{*}=$ [0.25-0.5]. These patterns are likely to be associated with the dominant mechanisms that cause the bottom layer to get coarser. In addition to this, larger foresets provide more space to sort material, making the sorting more efficient because there is more time for the coarse particle to be dragged down along the foreset. Some other physical processes linked to the coarsening of the bottom layer in the downstream direction are given in the Discussion section.

\section{Hydraulics of the experiment}

Channel hydraulics are crucial to interpretation of the experiment on delta progradation. A onedimensional numerical modelling using the hydraulic code HEC-RAS has been carried out. Water surface profiles for each of the long profiles of the delta obtained at times $t=138 \mathrm{~min}$, $238 \mathrm{~min}, 359 \mathrm{~min}, 510 \mathrm{~min}$ and $625 \mathrm{~min}$ have been computed. A detailed description of the numerical model can be found in Data S1.

Normal depth for each delta topset profile (computed using the $D_{90}$ of the mixture and the mean bed slope of each long profile) ranges between $0.11 \mathrm{~m}$ and $0.12 \mathrm{~m}$, whereas the corresponding water depth for the initial $2 \%$ slope is $0.067 \mathrm{~m}$. The critical depth is $0.086 \mathrm{~m}$. Thus, a subcritical backwater curve is expected between the brinkpoint and the dam, and a distinct water surface profile curve would develop along the delta topset depending on whether the water depth at the brinkpoint is higher, lower or equal to the normal depth. Computed long profiles demonstrate that the height of the dam at the downstream end imposes a water depth at the brinkpoint close to the normal depth: $0.091 \mathrm{~m}$ to $0.11 \mathrm{~m}$. Thus, a uniform flow profile develops on the delta topsets. Figure 4 illustrates the computed water surface elevation for the delta profiles after $t=63 \mathrm{~min}$. All five water surface profiles show some common features: a backwater curve in the ever-shorter part of the impoundment between the brinkpoint and the dam (with equal water surface elevations for all long profiles at the closest stations to the dam) and a uniform flow along the topset. Mean deviation of the water depth with respect to the normal depth, depending on the local channel slope (and also the surface texture in the last profile), ranges between $3.2 \%(t=625 \mathrm{~min})$ and $16.5 \% \quad(t=138 \mathrm{~min})$. Maximum values of Froude number $(\mathrm{Fr}=v / \sqrt{g h}$ where $v$ and $h$ are the mean flow velocity and the water depth, respectively) are near critical conditions in the delta topset profiles at stations close to the brinkpoint at $t=138 \mathrm{~min}, 238 \mathrm{~min}$ and $359 \mathrm{~min}$. Slightly lower values of the maximum Froude number $\left(F r_{\max }=0.85\right)$ are obtained for the last two delta topset profiles at $t=510 \mathrm{~min}$ and $t=625 \mathrm{~min}$. Mean Froude number along the topset gradually declines during the experiment $(\mathrm{Fr}=0.84$ to $0 \cdot 73)$.

\section{DISCUSSION}

The topset deposit aggrades during the first $359 \mathrm{~min}$ and starts to degrade afterwards: all material supplied from upstream and part of the topset that had been previously built up was, from $t=359 \mathrm{~mm}$ to the end of the run, emplaced along the foreset without contributing any longer to topset aggradation. The relationship between the delta celerity and the inverse of the delta front height can be used as a way to quantify how significant the topset aggradation (and degradation) is relative to the downstream progradation of the delta: if all material supplied from upstream deposited on the lee slope (without any change in the delta topset) so as to make the delta advance towards the dam, a perfectly linear relationship would exist between the delta celerity and the inverse of the delta front height. A nearly linear relationship $\left(R^{2}=0.92\right)$ is obtained when all data after $t=40 \mathrm{~min}$ are included in this analysis (Fig. 4), the correlation coefficient rises to 0.98 if only the last four delta profiles are considered. The high correlation coefficients evidence the minor significance of the storage of material on the topset slope rela- 
tive to the downstream advance of the delta regardless of whether the sediment supplied contributes to topset aggradation or not. The good agreement between these two variables also demonstrates the absence of suspended sediment in the experiment, some of which would otherwise have been wafted beyond the base of the foreset, and emplaced as a bottomset. The minor changes in the topset elevation (Fig. 6) and the low values of the curvatures of the long profiles are consistent with the uniform flow developed along the topset and predicted by the hydraulic model (Fig. 4).

Vertical sorting parameters in the $\psi$-scale have been normalized with the corresponding parameters of the feed grain-size distribution. A more detailed analysis could have used the relevant grain size of the sediment transport at the same vertical position where the sample was extracted. However, the material in the sampling points of the same vertical was deposited at different times. That is, insofar as the foreset slope is close to the angle of repose, the basal layers of a vertical cross-section were emplaced earlier than the layers above. Thus, a normalization of the vertical structure using the sediment transport grain-size distribution would only have been representative of the surface samples. Kleinhans $(2002,2005)$, in experiments of sorting in deltas and dunes, normalized the vertical

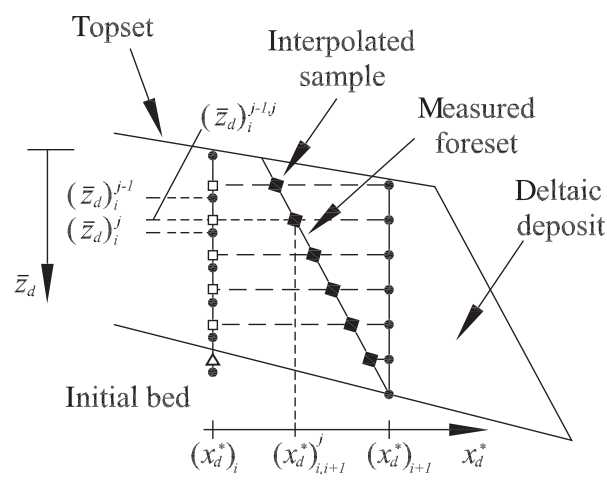

Fig. 13. Sketch illustrating how vertical samples were interpolated in order to estimate samples along the foreset at the time of emplacement. The original samples within the deltaic deposit are in bold circles, the squares are interpolation points in each vertical and the triangle corresponds to the samples of the parent material. A first vertical interpolation (resulting in the squares in the figure) is carried out to obtain the grain size at the same vertical position in the two consecutive sampling points (vertical lines in the figure). A second horizontal interpolation is done to calculate the grain sizes along the delta foreset (black diamonds). samples by using the average sediment transport grain-size distribution at various locations on the foreset, where the samples were collected. That is, Kleinhans sampled along a diagonal, whereas the present authors sampled in the vertical.

Comparisons between Fig. 8 and results obtained by Kleinhans (2005) are thus not straightforward. As noted above, Kleinhans (2005) appropriately collected sediment samples from the foreset, while in the present experiment, vertical locations characterizing the entire deposit were sampled. Thus, in order to compare the samples, horizontal and vertical interpolation between samples was carried out. A sketch of the sample interpolation procedure is illustrated in Fig. 13. It shows the position of two verticals (where samples were collected) and a foreset in between the two which illustrates the method of measurement used by Kleinhans. Note that the vertical interpolated samples falling within the initial bed (the triangle in Fig. 13) have not been used in the horizontal interpolation.

The vertical samples obtained at $x=5.5 \mathrm{~m}$, $6.5 \mathrm{~m}, 7.5 \mathrm{~m}$ and $8.5 \mathrm{~m}$ were projected following the methodology described above to the foreset profiles at times $t=238 \mathrm{~min}, 359 \mathrm{~min}$ and $510 \mathrm{~min}$. Because no significant vertical aggradation was observed in these profiles, the samples used are comparable to those of Kleinhans, despite differences in the experimental setup.

The results obtained by Kleinhans (2005) indicate that a correlation exists between bed sorting and delta height in the $x$ direction (see fig. 6 in Kleinhans, 2005), a pattern that was also found in the present research: the greater the height of the delta, the coarser the bottom layer. However, a larger degree of coarsening from topset-foreset break to base of the foreset (for a given sampling location in Fig. 8, compare the values of $\psi_{\mathrm{g}}^{*}$ at the uppermost and the lowermost layers of the deltaic deposit) was observed in the bottom layer of the experiments of Kleinhans, as opposed to the weaker degree of coarsening observed herein. This could be interpreted as the effect of different normalization schemes. Here, the geometric mean size $D_{\mathrm{g}}$ of the feed material was used for normalizing, while the geometric mean size $D_{\mathrm{g}}$ of the bedload at the brinkpoint was used by Kleinhans. In the present experiment, the feed material is systematically coarser than the sediment transport at the location where the samples collected were emplaced by the flow. Note that 


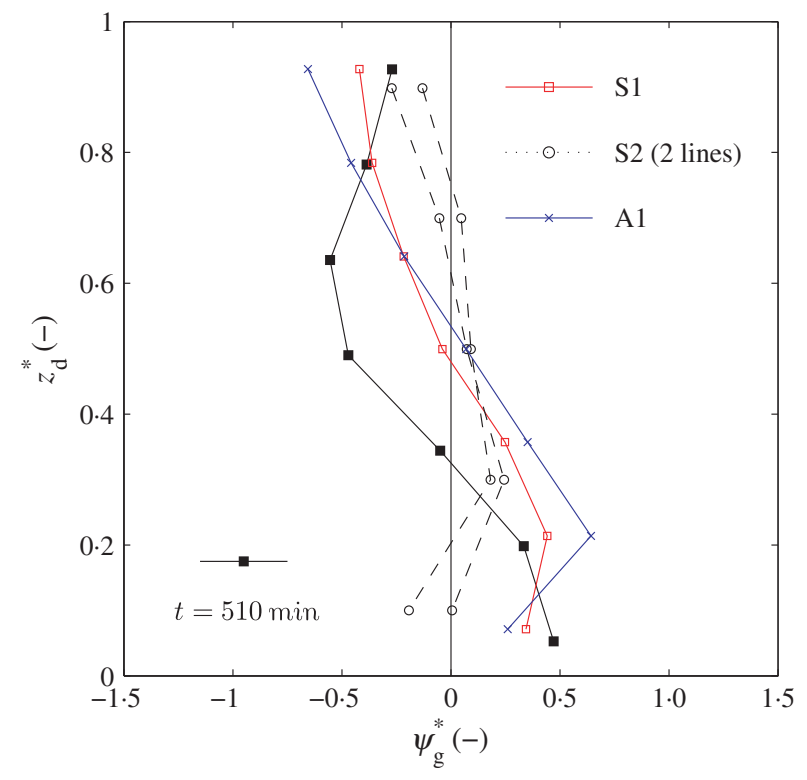

Fig. 14. Sorting along the long profile foreset at $t=510$ min compared with some representative data (tests S1, S2 - two lines - and A1) from Kleinhans (2005).

for this analysis, the pattern of increasing delta height as it approaches the dam will be expressed differently for different deltas: a higher antecedent bed slope and a higher rate of topset aggradation lead to a more strongly increasing delta height. Figure 14 illustrates a comparison of three representative results from Kleinhans (2005) (tests S1, S2 - two results - and A1 therein) and the present data on sorting of the geometric mean diameter projected to the foreset of the longitudinal profile at $t=510 \mathrm{~min}$ (lines with black squares). Thus, although the ordinate of the diagram is $z_{\mathrm{d}}^{*}$, the data points correspond to the foreset (as measured by Kleinhans and interpolated for the experiment herein). The top layer of the present results is somewhat coarser than the uppermost layer of the Kleinhans data. It is important to keep in mind, however, that the Kleinhans uppermost layer was somewhat below the surface itself. This disparity may be related to the difference in delta celerity. The range of delta speed progradation in Table 1 accounts for the three profiles along which vertical samples were projected (by interpolation). These values are between one and two orders of magnitude slower than those of Kleinhans.

A coarser top layer (with respect to deeper samples in the deltaic deposit; see Fig. 7) was also observed by Jopling (1965) in experiments with gravelly sand and glacial outwash sand. Some top coarsening was also reported by M. G. Kleinhans
(2011, pers. comm.). A probable explanation for this topmost coarsening is that the much slower values of delta progradation speed in the present experiment (as compared to Kleinhans) may lead to less frequent grain-flow events on the foreset, thus rendering the process of sorting less effective as the material falls from brinkpoint to the delta toe. This same phenomenon would also explain why the bottom layers observed in the present experiment are finer than those of Kleinhans. Previous investigations have linked grain-flow events to sediment transport rate on the delta topset (Allen, 1970; Hunter, 1985b; Hunter \& Kocurek, 1986; Nemec, 1990; Kleinhans, 2005), not to the delta speed propagation. However, there is a definable relation between these two when sediment transport takes place only through bedload: all sediment approaching the brinkpoint contributes to delta progradation into the water body. This phenomenon has been demonstrated before when analysing the dependences on the dimensionless grain flow number defined by Kleinhans (2005).

Another reason that might contribute to coarsen the top layer of the deltaic deposit is the formation of an equilibrium mobile armour. The role of the mobile armour is to prompt coarse fractions of the mixture to the surface. This material, intrinsically less mobile than the finest grain sizes, is over-represented on the bed surface so that the sediment transport texture matches that of the feed (Parker \& Klingeman, 1982). The formation of the mobile armour thus implies a surface coarsening. The formation of an equilibrium mobile armour layer has been modelled numerically by Viparelli et al. (2014). Topset bed slopes are close to those in equilibrium with the flow and feed rates from after $t=40 \mathrm{~min}$. However, this does not necessarily imply that the texture of the bedload transport had already matched that of the feed at this time: bedload texture might take longer to equal the feed grain-size distribution even though equilibrium slope has been achieved (FerrerBoix \& Hassan, 2014). Thus, it can be hypothesized that an equilibrium mobile armour develops towards the end of the run. In this case, a relative increase in the bed roughness would be expected which, in turn, would lead to an increase in the normal depth. The downstream boundary imposes a fixed water surface elevation at the dam. This boundary condition forces the erosion of the topset, especially when the delta foreset approaches the dam, and if the water depth at the brinkpoint resulting from 
the sediment emplacement is smaller than that imposed by the boundary conditions, which is observed in Fig. 6 where erosion of the topset after $t=359$ to 625 min progresses upstream.

In turn, the erosion of the topset might have left the upper layers of the delta below the surface exposed. Thus, these layers, initially finer than the former topset surface, become the surface of the delta, leading to a finer surface (compared to the feed, but coarser compared to the material below). In this regard, it is worth noting that the downstream fining of the topset is clearly noticeable between $x=550 \mathrm{~cm}$ and $850 \mathrm{~cm}$, where most of the topset degradation takes place (Fig. 6). It could be thought that coarse particles eroded from the delta topset might have been dragged down the foreset contributing to the coarsening of the bottom layer of the delta (Fig. 11). Furthermore, the degradation of the topset might have enhanced its coarsening, especially in those stations close to the brinkpoint. Given the limited height of the delta front, sediment accumulated on the wedge of material on top of the foreset that eventually avalanches might have been transported down to the bottom layer of the delta, amplifying the coarsening in the downstream direction. In this regard, Allen (1970) noticed that material dragged down along the lee face could stop at intermediate positions and be activated afterwards when pushed down by successive events. However, the possible amplification of the downstream coarsening is not fully supported because Fig. 11 shows downstream coarsening of the bottom layer at $x \leq 650 \mathrm{~cm}$ which was not affected by the erosion of the topset - recall that topset degradation started after $t=359 \mathrm{~min}$, the brinkpoint position of which is located at $x=717 \mathrm{~cm}$ (Figs 4 and 6).

The present experiment and those conducted by Kleinhans (2005) are both interested in how and why sediment is sorted in Gilbert-type deltas. However, the condition of the experiment presented herein is essentially different from those carried out by Kleinhans (2005). This is because, as mentioned before, the downstream boundary condition in the present experiment is such that it initially imposes a water depth at the brinkpoint close to the normal depth. This is the reason why delta evolves during the first six hours of run with nearly no aggradation. The overall effect of the formation of an armour layer on the topset, the decreasing of the speed at which the delta progrades and the fixed water surface elevation imposed as a boundary condition downstream forces the delta to degrade after $t=359 \mathrm{~min}$.
Finally, the experiment shows that when bedload dominates, no bottomset is emplaced from suspended load, so that the associated downstream fining pattern from brinkpoint to dam shown in Fig. 1 is not observed. This pattern of downstream fining is observed when suspended load is an important fraction of the total load (Jopling, 1965). Conversely, in deltas emplaced by bedload, coarser material is deposited on the bottom layer, such that coarser material accumulates closer to the dam. This condition holds at least for the experiment conducted here.

\section{Comparison with a sorting model}

The experiments carried out by Kleinhans (2005) were focused on studying vertical sorting on the delta lee face due to grain flow. The aim of the experiment presented herein is, however, to describe the spatial variation in the entire deposit emplaced by a prograding delta. Nevertheless, insofar as every point within the deposit was formed by the bed material falling along the lee face, the Kleinhans experiments, even though different in scope, can be used for the purpose of comparison with the present work. In particular, a check can be made as to whether the equation presented by Kleinhans (2005) for lee face (foreset) sorting can be applied to the experiment herein.

Here, the grain-size distribution along the present delta is compared with the predictions of the empirical sorting model presented by Kleinhans (2005). The model has the advantage of simplicity but, as pointed out by Blom \& Kleinhans (2006), one drawback is that mass conservation is not satisfied. In this regard, Blom \& Kleinhans (2006) present a sorting model, calibrated and validated with delta and dune experiments, which does satisfy mass conservation. However, the present research warrants a direct comparison with the Kleinhans sorting model.

A key parameter of the Kleinhans model is a dimensionless sorting slope along the lee face, defined as follows:

$$
\mathrm{SS}^{*}=\frac{1}{\sigma_{T}} \frac{d \psi^{*}}{d\left(1-z_{\mathrm{d}}^{*}\right)}
$$

where $\sigma_{T}$ is the arithmetic standard deviation computed in $\psi$-scale of the mixture passing over the brinkpoint, i.e. $\sigma$ according to Eq. 3 , SS* is equivalent in scope to Eq. 8 except for the inclusion of $\sigma_{T}$ : the expression (8) linearly discretizes the derivative in the right-hand side of Eq. 10. 


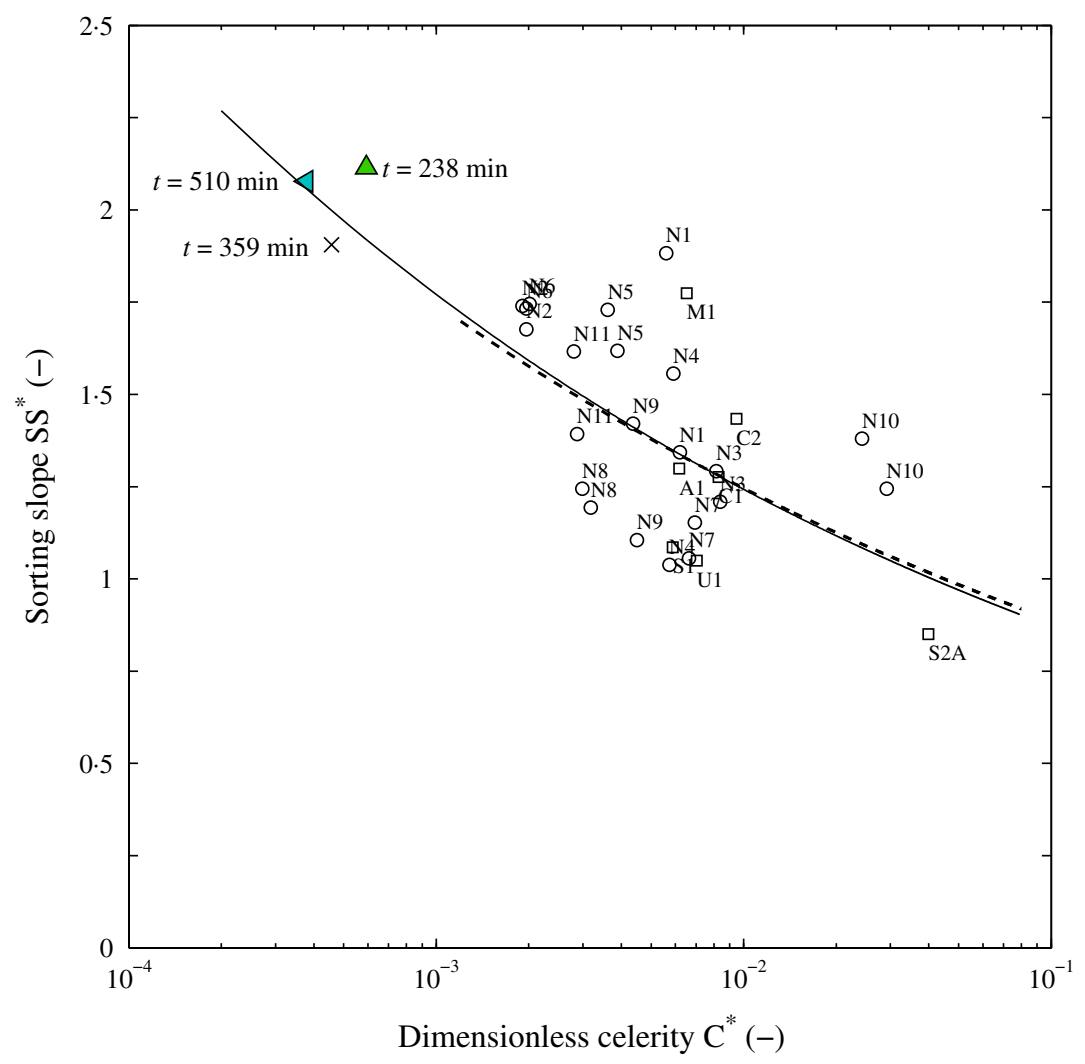

Fig. 15. Relation between the dimensionless sorting slope SS* and dimensionless delta celerity progradation $C^{*}$. Figure includes the present data at three different times ( $t=238 \mathrm{~min}, 359 \mathrm{~min}$ and $510 \mathrm{~min}$ ) and data from Kleinhans (2005) in circles and white squares. The data from Kleinhans has been amended to correct misprints, as communicated directly by M. G. Kleinhans.

According to Kleinhans (2005) the celerity of the prograding delta is expressed in dimensionless form as:

$$
C^{*}=\frac{C}{\sqrt{\operatorname{Rg} D_{\mathrm{g}, T}}}
$$

in which $D_{\mathrm{g}, T}$ is the geometric mean diameter of the bedload going over the brinkpoint (topsetforeset break). There are some misprints in Kleinhans (2005). Here corrected values obtained directly from the author are used. The amended Kleinhans relation for SS* versus $C^{*}$ reads as follows:

$$
\mathrm{SS}^{*}=0 \cdot 64 C^{*-0 \cdot 15}
$$

Figure 15 plots the results of SS* versus $C^{*}$ for the Kleinhans tests, together with the values corresponding to the present experiment. The dashed line represents Eq. 12. Fitting a curve to the complete set of data (the data herein and that of Kleinhans), only a slight variation in the coefficient of Eq. 12 is obtained: the coefficient
$0 \cdot 64$ is modified to $0 \cdot 61$. The minor differences found between the two curves means that the equation proposed by Kleinhans (2005) represents a good approximation to obtain the sorting slope in Gilbert-type deltas that prograde at low celerities (such as those registered in the present experiment).

Equation 12 allows the present authors to obtain an expression for the vertical sorting of the geometric mean grain size (in the $\psi$-scale) as follows:

$$
\psi_{\mathrm{g}}^{*}\left(z^{*}\right)=-\sigma_{T}\left[\left(1-z^{*}\right)-\left(1-z_{0}^{*}\right)\right] 0 \cdot 64 C^{*-0 \cdot 15}
$$

where $z_{0}^{*}$ is the dimensionless vertical height at which $\psi_{\mathrm{g}}$ equals $\psi_{\mathrm{g}, \mathrm{f}}$ Implicit in Kleinhans (2005) is the assumption that $z_{0}^{*}$ should be located at half the delta height. Equation 13 has been obtained by substituting SS* from Eq. 12 into Eq. 10 and by assuming a linear variation of $\psi_{\mathrm{g}}^{*}$ along the dimensionless vertical coordinate $\bar{z}_{\mathrm{d}}-$ equal to $1-z_{\mathrm{d}}^{*}$, Eq. 7 - on the right-hand 

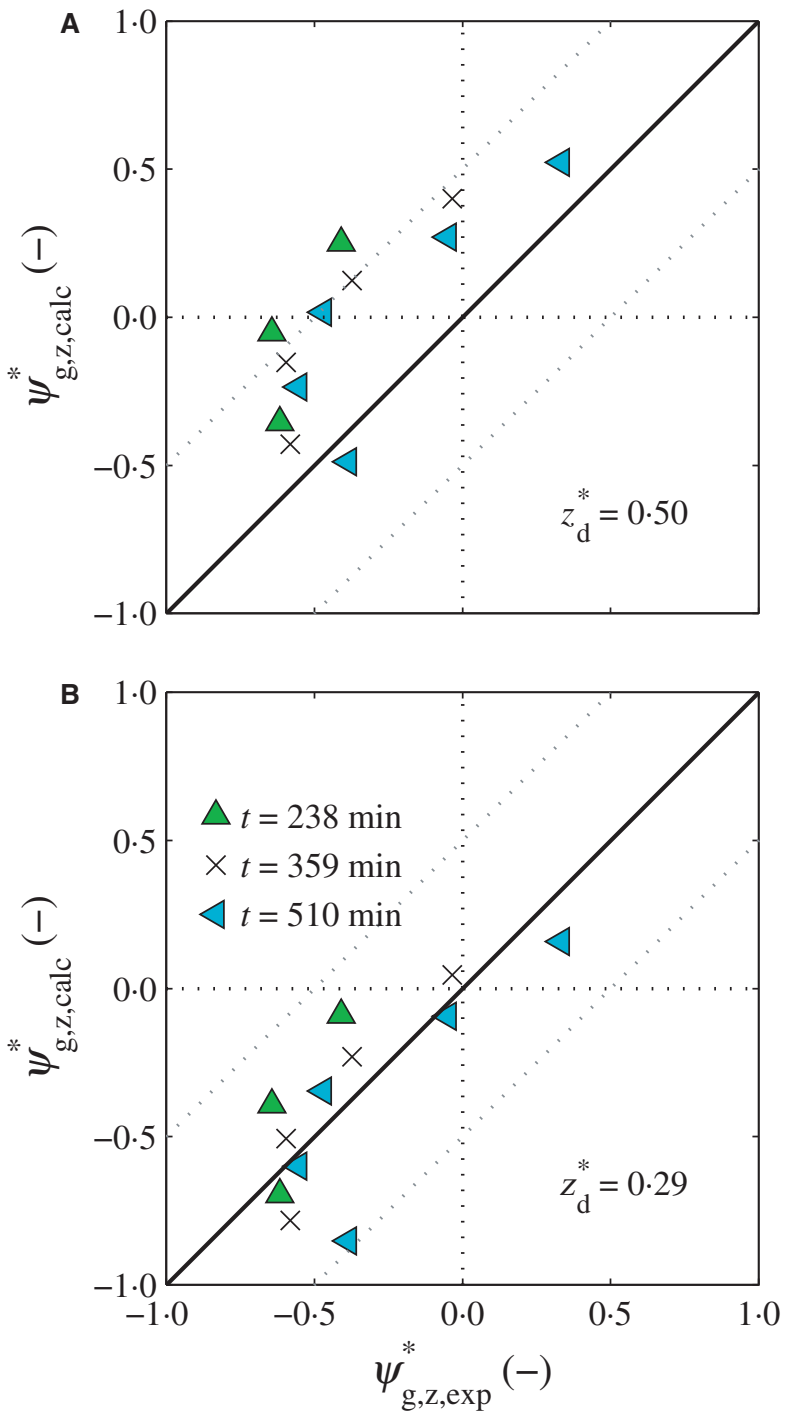

Fig. 16. Performance of the empirical model for lee face sorting proposed by Kleinhans (2005) as adjusted above, i.e. Eq. 11. The plot shows measured values of $\psi_{\mathrm{g}}^{*}$ at various levels $\mathrm{z}\left(\psi_{\mathrm{g}, z, \exp }^{*}\right)$ versus calculated values $\left(\psi_{\mathrm{g}, z, \mathrm{calc}}^{*}\right)$. Comparison using original value $z_{0}^{*}=0 \cdot 5$ of Kleinhans is shown in (A), and comparison with the amended value $z_{0}^{*}=0 \cdot 29$ is shown in (B). Dashed lines above and below the main diagonal illustrate the errors in the range of $\psi_{\mathrm{g}}^{*} \pm 1 / 2$ with respect the perfect agreement, i.e. between $\left[(1 / \sqrt{2}) D_{\mathrm{g}}, \sqrt{2} D_{\mathrm{g}}\right]$.

side of Eq. 10. The negative sign in Eq. 13 accounts for the downward coarsening of the foreset. As illustrated below, a lower value of $z_{0}^{*}$ pertains to the present experiment.

Figure 16 illustrates the comparison between measured and computed values of $\psi_{\mathrm{g}, z}^{*}$ according to Eq. 13. Each marker type in Fig. 16 plots the interpolated sediment samples for the foreset profiles at $t=238 \mathrm{~min}, 359 \mathrm{~min}$ and $510 \mathrm{~min}$. Figure 16A shows the comparison between the complete experimental set of data and the computed values using the new Eq. 13 (i.e. with the adjusted coefficient $0 \cdot 61$ ), but using the value $z_{0}^{*}=0.5$ of Kleinhans (2005). All values are bounded by the range $\psi_{\mathrm{g}}^{*} \pm 1$, but some of them fall outside of the lines corresponding to $\psi_{\mathrm{g}}^{*} \pm 1 / 2$ which bracket the line of perfect agreement. This means that computed values are contained in the range $\left[(1 / 2) D_{\mathrm{g}}, 2 D_{\mathrm{g}}\right]$.

Equation 13 is linearly dependent on the location of $z_{0}^{*}$. Furthermore, as can be seen in Figs 8 and 14 , it seems that in the present experiment, the point in the vertical $z_{0}^{*}$ where $\psi_{\mathrm{g}}=\psi_{g, f}$ is systematically located within the lower half of the delta height. A position $z_{0}^{*}=0.29$ is obtained when minimizing the root mean square deviation between observed and predicted values of $\psi_{\mathrm{g}, \mathrm{z}}^{*}$. Figure 16B illustrates the improvement in the calculated values of sorting with the new position of $z_{0}^{*}$; now all of them are contained within the range $\psi_{\mathrm{g}}^{*} \pm 1 / 2$, i.e. between $\left[(1 / \sqrt{2}) D_{\mathrm{g}}, \sqrt{2} D_{\mathrm{g}}\right]$. Despite the scatter, the predictions by the empirical model presented by Kleinhans (2005), as modified here, appear to be reasonable, taking into account that the delta celerities measured herein are between one and two orders of magnitude slower than those of Kleinhans (2005) (Fig. 15), and that the sediment samples used to test the model were not extracted from the delta foreset itself, but from vertical lines located at different stations along the delta.

Slower delta celerities are assumed to be responsible for the drop in the point $z_{0}^{*}$ at which $\psi_{\mathrm{g}}$ equals $\psi_{\mathrm{g}, \mathrm{f}}$. The slower the rate of delta progradation, the fewer the number of grain-flow events that occur along the foreset. Thus, an over-representation of the coarser particles in the upper layer is expected. By mass conservation, less coarse particles will be located in the lower layer, and thus a fall in $z_{0}^{*}$ should occur. Further, as noticed above, smaller delta celerities lead to fewer grain-flow events. If the sediment transport rate at the brinkpoint is constant as the delta progrades downstream (in agreement with the uniform flow developed on the topset), an increasing volume of sediment of grain-flow events in the downstream direction can occur. This would lessen the efficiency of sorting processes on the topset (Kleinhans, 2004). As mentioned before, the formation of a mobile armour layer might have also contributed to the coarsening of the surface sample. The drop of $z_{0}^{*}$ merely illustrates the consequences of the aforementioned processes in the sorting processes along foresets in Gilbert-type deltas. 


\section{CONCLUSIONS}

An experiment was performed on the progradation of a Gilbert-type delta with a poorly sorted sandy gravel. Sediment transport along the topset was only as bedload. The bed profile evolution was measured, and the celerity of delta progradation was calculated. Water surface profiles were calculated by means of a calibrated hydraulic model.

The delta prograded towards the dam with little topset aggradation during the first six hours of the run; this was caused by the water depth imposed to the brinkpoint, which was close to the normal depth. The parts of the topset closest to the dam started to degrade afterwards, as a result of the formation of a mobile armour and the water configuration of the experiment, that imposed a fixed water surface elevation at the outlet. The material eroded from the topset and dragged down along the foreset to the base of the delta has been found to have minor implications in the coarsening of the bottom layer of the delta.

The stratigraphy of the delta was analysed by extensive sampling, both in the vertical and in the streamwise directions. It was found that there is a characteristic vertical sorting of the material that forms the delta: the grain-size distribution towards the bottom of the deposit is coarser than the sediment feed material. This bottom layer coarsening is accompanied by a vertical fining in the central part of the body of the delta compared to the feed grain-size distribution: large particles do not stay in this zone. Rather they are dragged to the bottom as they fall over the delta foreset. Furthermore, the top layer of the deposit was observed to be coarser than the material in the central part of the deposit (but finer than the feed); this may be related to the slow delta progradation celerity of the present experiment, and due to the formation of a mobile armour layer and the degradation of the part of the topset closest to the dam. It was found that coarsening of the bottom layer is related to delta height: the higher the delta, the coarser the mean grain size at the base of the foreset, and thus the base of the deposit, which means that when bedload dominates, the closer the proximity to the dam, the coarser the bottom layer, at least for the experiment reported here. This coarsening process is related to the increasing probability for a coarse particle to fall to the base of the foreset as the height of the delta increases. Finally, a tendency for downstream fining within the top layer of the deposit was observed, with coarser particles depositing at locations close to the point of sediment feed. However, the magnitude of downstream fining in the top layer is much weaker than the magnitude of vertical sorting.

Bed material sorting patterns were described well by the empirical model presented by Kleinhans (2005). The modest variations of these parameters were back-calculated from the measured grain-size distribution. This good agreement was obtained despite the fact that the data were collected in very different ways. That is, the data of Kleinhans (2005) were obtained by gathering appropriate measurements from the foreset itself, whereas the present experiment sampled the entire deltaic deposit. Nonetheless, the fact that the deltaic deposit of this experiment can be considered as formed by sediment emplacement in the foreset (insofar as no significant topset aggradation occurred) aids comparison with the Kleinhans experiments. Interpolation was used to cast the present data into a form directly comparable with those of Kleinhans. The experimental results for both delta progradation and sediment sorting provide useful data for testing morphodynamic models of delta progradation associated with a sediment supply that consists of a poorly sorted mixture of sand and gravel (e.g. Viparelli et al., 2010a,b, 2011, 2014).

\section{ACKNOWLEDGEMENTS}

This research was funded in part by the National Center for Earth-surface Dynamics, a Science and Technology Center and by the US National Science Foundation, under agreement EAR-0120914. The readers can freely access the data from this paper by contacting the first author. Thanks to M. G. Kleinhans for providing all data and specific details of his experiments. Comments from the two reviewers Astrid Blom and Brandon McElroy and the Associate Editor David Mohrig helped us improved the paper.

\section{REFERENCES}

Allen, J. (1965) Sedimentation to the lee of small underwater sand waves: an experimental study. J. Geol., 73, 95-116.

Allen, J. (1970) The avalanching of granular solids on dune and similar slopes. J. Geol., 78, 326-351.

Bagnold, R.A. (1954) Experiments on a gravity-free dispersion of large solid spheres in a Newtonian fluid under shear. Proc. Roy. Soc. London. A Math. Phys. Sci. 225, 49-63. 
Blom, A. and Kleinhans, M.G. (2006) Modelling sorting over the lee face of individual bed forms. In: River Flow 2006 (Eds A. Dittrich, K. Koll, J. Aberle and P. Geisenhainer), pp. 807-816. Taylor \& Francis, London.

Blom, A. and Parker, G. (2004) Vertical sorting and the morphodynamics of bed form-dominated rivers: a modeling framework. J. Geophys. Res. Earth., 109, F02007.

Blom, A., Ribberink, J.S. and de Vriend, H.J. (2003) Vertical sorting in bed forms: flume experiments with a natural and trimodal sediment mixture. Water Resour. Res., 39, 1025.

Blom, A., Parker, G., Ribberink, J.S. and de Vriend, H.J. (2006) Vertical sorting and the morphodynamics of bedform-dominated rivers: an equilibrium sorting model. J. Geophys. Res. Earth., 111, F01006.

Bornhold, B. and Prior, D.B. (1990) Morphology and sedimentary processes on the subaqueous Noeick River Delta, British Columbia, Canada. In: Coarse-Grained Deltas (Eds A. Colella and D.B. Prior), pp. 169-181. Blackwell Publishing Ltd., Oxford, UK.

Cantelli, A., Paola, C. and Parker, G. (2004) Experiments on upstream-migrating erosional narrowing and widening of an incisional channel caused by dam removal. Water Resour. Res., 40, W03304.

Carling, P.A. and Glaister, M. (1987) Rapid deposition of sand and gravel mixtures downstream of a negative step: the role of matrix infilling and particle overpassing in the process of bar front accretion. J. Geol. Soc. London, 144, 543-551.

Evans, J., Mackey, S., Gottgens, J. and Gill, W. (2000) Lessons from a dam failure. Ohio J. Sci., 100, 121-131.

Ferrer-Boix, C. (2011) River incision due to gravel mining and dam removal. Mathematical and experimental study, $\mathrm{PhD}$ thesis, Technical University of Catalunya, Barcelona.

Ferrer-Boix, C. and Hassan, M.A. (2014) Influence of the sediment supply texture on morphological adjustments in gravel-bed rivers. Water Resour. Res., 50, 1-23. doi: 10.1002/2013WR015117.

Ferrer-Boix, C., Martín-Vide, J.P. and Parker, G. (2014) Channel evolution after dam removal in a poorly sorted mixture. Experiments and numerical model. Water Resour. Res., 50, 1-23. doi: 10.1002/2014WR015550.

Gilbert, G.K. (1890) Lake Boneville, Technical report. United States Geological Survey, Washington, 438 pp.

Hotchkiss, R.H. (1989) Reservoir sedimentation and sediment sluicing: experimental and numerical analysis, PhD thesis. University of Minneapolis.

Hotchkiss, R.H. and Parker, G. (1991) Shock fitting of aggradational profiles due to backwater. J. Hydraul. Eng., 117, 1129-1144.

Hunter, R. (1985a) Subaqueous sand-flow cross strata. J. Sed. Petrol., 55, 886-894.

Hunter, R. (1985b) A kinematic model for the structure of lee-side deposits. Sedimentology, 32, 409-422.

Hunter, R. and Kocurek, G. (1986) An experimental study of subaqueous slipface deposition. J. Sed. Petrol., 56, 387-394.

Jopling, A.V. (1965) Laboratory study of the distribution of grain sizes in cross-bedded deposits. In: Primary Sedimentary Structures and Their Hydrodynamic Interpretation (Ed. G.V. Middleton), SEPM Spec. Publ., 12, 53-65.

Kleinhans, M.G. (2002) Sorting out sand and gravel: sediment transport and deposition in sand-gravel bed rivers, $\mathrm{PhD}$ thesis. Faculty of Geographical Sciences, Utrecht University.

Kleinhans, M.G. (2004) Sorting in grain flows at the lee side of dunes. Earth Sci. Rev., 65, 75-102.
Kleinhans, M.G. (2005) Grain-size sorting in grainflows at the lee side of deltas. Sedimentology, 52, 291-311.

Lorenzo-Trueba, J. and Voller, V. (2010) Analytical and numerical solution of a generalized Stefan problem exhibiting two moving boundaries with application to ocean delta formation. J. Math. Anal. Appl., 366, 538-549.

Muto, T., Yamagishi, C., Sekiguchi, T., Yokokawa, M. and Parker, G. (2012) The hydraulic autogenesis of distinct cyclicity in delta foreset bedding: flume experiments. J. Sed. Res., 82, 545-558.

Nemec, W. (1990) Aspects of sediment movement on steep delta slopes. In: Coarse-Grained Deltas (Eds A. Colella and D.B. Prior), pp. 29-73. Blackwell Publishing Ltd., Oxford, UK.

Parker, G. and Klingeman, P. (1982) On why gravel bed streams are paved. Water Resour. Res., 18, 1409-1423.

Saito, Y. (2011) Delta-front morphodynamics of the Kurore River fan delta, central Japan. In: RCEM 2011. River, Coastal and Estuarine Morphodynamics (Eds X. Shao, Z. Wang and G. Wang), pp. 969-976. Tsinghua University Press, Beijing.

Seal, R., Paola, C., Parker, G., Southard, J.B. and Wilcock, P.R. (1997) Experiments on downstream fining of gravel: I. Narrow channel runs. J. Hydraul. Eng., 123, 874-884.

Sohn, Y., Kim, S., Hwang, I., Bahk, J., Choe, M. and Chough, S. (1997) Characteristics and depositional processes of large-scale gravelly Gilbert-type foresets in the Miocene Doumsan fan delta, Pohang Basin, SE Korea. J. Sed. Res., 67, 130-141.

Vanoni, V.A. (ed.) (1975) Sedimentation Engineering. American Society of Civil Engineers, New York, NY.

Viparelli, E., Haydel, R., Salvaro, M., Wilcock, P.R. and Parker, G. (2010a) River morphodynamics with creation/ consumption of grain size stratigraphy 1: laboratory experiments. J. Hydraul. Res., 48, 715-726.

Viparelli, E., Sequeiros, O.E., Cantelli, A., Wilcock, P.R. and Parker, G. (2010b) River morphodynamics with creation/ consumption of grain size stratigraphy 2: numerical model. J. Hydraul. Res., 48, 727-741.

Viparelli, E., Blom, A. and Parker, G. (2011) Numerical prediction of the stratigraphy of bedload-dominated deltas: preliminary results. In: RCEM 2011. River, Coastal and Estuarine Morphodynamics (Eds X. Shao, Z. Wang and G. Wang), pp. 552-562. Tsinghua University Press, Beijing, China.

Viparelli, E., Blom, A., Ferrer-Boix, C. and Kuprenas, R. (2014) Comparison between experimental and numerical stratigraphy emplaced by a prograding delta. Earth Surf. Dyn., 2, 323-338.

Wong, M., Parker, G., DeVries, P., Brown, T. and Burges, S. (2007) Experiments on dispersion of tracer stones under lower-regime plane-bed equilibrium bed load transport. Water Resour. Res., 43, W03440.

Manuscript received 10 November 2013; revision accepted 16 January 2015

\section{Supporting Information}

Additional Supporting Information may be found in the online version of this article:

Data S1. Hydraulics of the experiment. 